\title{
PARENTESCO Y PATRIMONIO \\ EN LA BAJA Y MEDIA NOBLEZA CASTELLANA \\ EN LA PLENA EDAD MEDIA (C. 1200-C. 1250). ALGUNOS EJEMPLOS ${ }^{1}$
}

\author{
LAND AND KINSHIP AMONG THE \\ CASTILIAN LESSER NOBILITY IN THE CENTRAL MIDDLE AGES
}

(C. 1200-C. 1250). SOME CASE STUDIES

\section{IGNACIO ÁLVAREZ BORGE Universidad de La Rioja}

\begin{abstract}
Resumen: Aunque los estudios sobre la nobleza castellana en la Edad Media han experimentado un desarrollo considerable y una importante renovación en las últimas décadas, los períodos alto y plenomedieval y los sectores de la nobleza no magnaticia todavía son poco conocidos. En este artículo se reconstruye la sucesión genealógica y los dominios de un grupo que, en general, podemos calificar como baja nobleza. Mediante el estudio detallado de ambos aspectos - prosopografía y dominios- es posible establecer matices al concepto general de baja nobleza y avanzar en un conocimiento más detallado de ese sector de la nobleza.
\end{abstract}

Palabras clave: Plena Edad Media; Castilla; Nobleza, Baja Nobleza; Señoríos; Dominios; Parentesco.

\begin{abstract}
Even when studies about castilian nobility during the Middle Ages have gone further and had an important renovation during the last decades, the High and Central Middle Ages and the sectors below the upper levels of the nobility are quite less known. In this paper I will try to study the succession and properties of a kindred that, in quite a general sense, we may consider "lesser nobility". Both sides of the study - prosopography and properties - will allow us a deeper understanding and knowledge of such an important sector of the nobility.
\end{abstract}

Keywords: Central Middle Ages; Castile; Nobility; Lesser nobility; Lordships; Properties; Kinship.

\section{SUMARIO}

Introducción.- 1. Ordoño Pérez I y Urraca Fernández.- 2. García Fernández de Villamayor.3. Ordoño Pérez II de Cabia y sus descendientes.- 4. La familia de Vela García.- 5. Los Castil Sarracín.- Recapitulación.

${ }^{1}$ Este trabajo se ha realizado en el marco de un Proyecto de Investigación financiado por el Ministerio de Educación y Ciencia (HUM2005-03424) y dirigido por C. Estepa. 


\section{INTRODUCCIÓN}

Los estudios sobre la nobleza castellana en la Edad Media han experimentado un importante desarrollo en los últimos años; en las últimas dos décadas a grandes rasgos. Por lo que se refiere a la baja nobleza, en un estudio reciente sobre los hidalgos y la hidalguía universal en el País Vasco, J.R. Díaz de Durana ha realizado un amplio estado de la cuestión centrándose en varios ámbitos de la corona de Castilla ${ }^{2}$. Asumo sus planteamientos y remito a ese trabajo exhaustivo, de manera que no creo necesario realizar aquí una amplia introducción historiográfica que, en buena medida sería redundante. Pero sí me parece conveniente referirme a algunos aspectos, unos más generales, otros más concretos, que ayudarán al lector a situarse en el panorama historiográfico general y en mis propios planteamientos previos.

El desarrollo historiográfico no ha sido igual para todos los momentos del largo período medieval, ni para todos los sectores de la nobleza. Conviene destacar estos aspectos porque no se debe generalizar mecánicamente lo conocido para un sector de la nobleza (por ejemplo, la alta nobleza) en un momento determinado (por ejemplo, la Baja Edad Media) a los otros sectores de la nobleza o en otros períodos, ni en cuestiones sociales, ni económicas, ni políticas. Esa generalización será, en todo caso, una hipótesis a contrastar, pero no una conclusión. En mi opinión hay dos claros desequilibrios en el desarrollo historiográfico. Por un lado, conocemos mucho mejor la nobleza en la Baja Edad Media que en los períodos anteriores alto y plenomedievales. Por otro lado, conocemos mucho mejor la alta nobleza que los otros sectores nobiliarios, a los que generalizando excesivamente solemos denominar baja nobleza. Evidentemente, no se trata de desquilibrios caprichosos, sino que vienen determinados por la cantidad y la calidad de las fuentes disponibles ${ }^{3}$.

Cuando hablamos de nobleza castellana medieval, es inevitable referirse a S. de Moxó y a su conocido estudio sobre "De la nobleza vieja a la nobleza nueva", entre otras razones porque tiene mucho que ver con el

${ }^{2}$ J.R. DÍAZ DE DURANA, La otra nobleza. Escuderos e hidalgos sin nombre y sin historia. Hidalgos e hidalguía universal en el Pais Vasco al final de la Edad Media (1250-1525), Vitoria, 2004 , pp. 23 y Ss. Y una revisión de la historiografía europea en R. PASTOR; C. ÉSTEPA; I. ALFONSO; J. ESCALONA; C. JULAR; E. PASCUA Y P. SÁNCHEZ, Baja Nobleza: aproximación a la historiografía europea y propuestas para una investigación, "Historia Social", 20 (1994), pp. 2345 .

${ }^{3}$ No haré una revisión de los estados de la cuestión que se han ido publicando en los últimos años al ritmo que iban aumentando los trabajos. El libro de Durana citado en la nota anterior es muy completo y su bibliografía es exhaustiva (véanse especialmente las referencias de M.A. Ladero Quesada, M.C. Quintanilla, J.M. Monsalvo o P. López Pita). Puede verse también una recopilacion bibliográfica en La nobleza en España. "BIHES. Bibliografías de Historia de España", 11 (2001), 2 vols., especialmente vol. 1. El estado de la cuestión mas reciente que conozco específicamente sobre la nobleza castellano-leonesa en la Plena Edad Media es el de P. MARTÍNEZ SOPENA, La prosopografía de la nobleza castellano-leonesa (siglos XI-XIII). Balance y perspectivas, en VV. AA., La prosopografía como método de investigación sobre la Edad Media, Zaragoza, 2006, pp.' 119-143. Como obras generales, puede verse I. BECEIRO y R. CÓRDOBA, Parentesco, poder y mentalidad. La nobleza castellana, siglos XII-XV , Madrid, 1990; y M.C. GERBET, Las noblezas españolas en la Edad Media. Siglos XI-XIV, Madrid, 1997. Para la Baja Edad Media hay que destacar los numerosos trabajos de A. Franco Silva. 
desarrollo historiográfico que he mencionado. Moxó no estudio el conjunto de la nobleza sino la alta nobleza, a la que definió con una cierta precisión en el período plenomedieval (recuerdense los tres elementos característicos: el patrimonio, el linaje y la privanza $)^{4}$. Pero transmitió también la idea de que el resto de la nobleza que quedaba fuera de esa definición formaba un colectivo más o menos homogéneo: la baja nobleza.

Entre los estudios que se han ocupado de analizar la baja nobleza en la época plenomedieval han tenido un peso importante los que se han orientado a los análisis léxicos e institucionales (con una clara interrelación entre ambos planteamientos), estudios representativos de una historiografía que podríamos llamar tradicional. ¿Qué eran los infanzones? ¿Qué eran los hidalgos? ¿Qué los caballeros? ¿Qué la caballería villana? ${ }^{5}$ Las aportaciones concretas han sido desiguales y considero necesarias estas propuestas, pero también claramente insuficientes. Desde los años 80 la renovación y el desarrollo de este tipo de estudios se ha concretado en centrar los análisis no en la definición institucional -aunque esta no sea, en absoluto, despreciable-, sino en la definición social y económica de la baja nobleza. Una definición social y económica que implica también saber con alguna preción de quién se está hablando en cada caso, por lo que resulta necesario un trabajo de reconstrucción genealógica y prosopográfica; reconstrucción que resulta muy difícil en las épocas alto y plenomedieval por las características de la documentación conservada.

Por lo que se refiere al marco cronológico y espacial del que me ocupo en este trabajo, merece destacarse el importante esfuerzo realizado en su día por P. Martínez Sopena para tratar de definir, desde esos puntos de vista, la baja nobleza de la zona de la Tierra de Campos occidental entre los siglos X y XIII a los que él llamó "los caballeros locales". Con un planteamiento similar, C. Reglero estudió también después "los señoríos de la nobleza regional y local" de la zona de los Montes de Torozos entre los siglos XII-XIV ${ }^{6}$. Cuando se estudian los dominios y señoríos que dan contenido a los fundamentos sociales y económicos de la baja nobleza resulta claro que la expresión baja nobleza, es insuficiente por ser demasiado generalizadora. Resulta evidente que no todo lo que no era alta nobleza formaba un colectivo

\footnotetext{
${ }^{4} \mathrm{~S}$. DE Moxo, De la nobleza vieja a la nobleza nueva. La transformación nobiliaria castellana en la Baja Edad Media "Cuadernos de Historia. (Anexos de la revista Hispania)", 3, pp. 1-210, especialmente pp. 1-31.

${ }^{5}$ Por ejemplo, C. PESCADOR, La caballería popular en León y Castilla "Cuadernos de Historia de España", 33-34 (1961), pp. 101-238; 35-36 (1962), pp. 56-201; 37-38 (1963), pp. 88-198; y 39-40 (1964) pp. 169-200. M.C. CARLE, Infanzones, e hidalgos, "Cuadernos de Historia de España", XXXIII-XXXIV (1961), pp. 56-101; M.I. PÉREZ DE TUDELA, Infanzones y caballeros. Su proyección en la esfera nobiliár castellano-leonesa (siglos IX-XI), Madrid, 1979; o J.M. LACARRA, En torno a la propagación de la voz 'hidalgo', en Investigaciones sobre Historia de Navarra, Pamplona, 1983, pp. 201-219.

${ }^{6} \mathrm{P}$. MARTÍNEZ SOPENA, La Tierra de Campos occidental. Parentesco, poder y comunidad del siglo $X$ al XIII, Valladolid, 1985, pp. 359-367 y 405-422. C.M. REGLERO DE LA FUENTE, LOS señoríos de los Montes de Torozos. De la repoblación al Becerro de las Behetrías (siglos X-XIV), Valladolid, 1993, pp. 137-147. Véase también la obra más reciente de A. BARÓN FARALDO, Grupos y dominios aristocráticos en la Tierra de Campos oriental. Siglos X-XIII, Palencia, 2006, pp. 237-324.
} 
homólogo. Reglero oportunamente en su trabajo habla de nobleza regional y nobleza local, pero quien ha realizado un análisis más detallado ha sido $\mathrm{C}$. Estepa en su reciente estudio sobre las behetrías castellanas. Un estudio mucho más amplio que cualquier otro publicado hasta ahora sobre familias y grupos familiares de la baja nobleza castellana y sus dominios en la Plena Edad Media. Estepa propone distinguir la nobleza de caballeros de los hidalgos locales y, a su vez, dentro de la nobleza de caballeros, cabría hablar de nobleza regional, nobleza comarcal y nobleza local ${ }^{7}$. Sus planteamientos amplían y enriquecen mucho el panorama, además de aportar un enorme volumen de información genealógica y prosopográfica, hasta ahora totalmente desconocido ${ }^{8}$.

En ese contexto se sitúan las páginas siguientes, que pretenden una aproximación a la reconstrucción de un amplio grupo familiar y de sus dominios en el período c. 1200-c. 1250. Un grupo diverso e integrado por gentes, parientes entre sí, que igualmente tenía una posición económica, social y política también diversa. La documentación es escasa y fragmentaria y por ello las conclusiones sobre la posición de cada individuo son provisionales, pero dentro de este grupo familiar podemos encontrar todos o casi todos los grados y escalones del sector nobiliario que no era alta nobleza; e incluso también algún miembro de este grupo alcanzó, gracias a su carrera política y a sus apoyos en la corte, la alta nobeza. Pero, como ya indicaba Estepa en su exhaustivo estudio, no siempre podemos atribuir a unos u otros individuos una posición precisa en los distintos niveles que podemos distinguir dentro de lo que genéricamente veníamos considerando como baja nobleza. Los grupos y la clasificación propuesta por este autor no son grupos cerrados, con un definición precisa y bien delimitados, son grupos abiertos y la clasificación pretende, más bien, guiarnos por un mundo amplio y complejo para poder avanzar en el estudio. La propia posición de cada individuo podía cambiar a lo largo del tiempo, tanto en sentido ascendente como descendente.

En el título de este artículo hablo de baja y media nobleza con una cierta ambigüedad, porque mis datos no me permiten hacer una clasificación más detallada, que sólo puede realizarse a partir de volúmenes de información mucho más amplios. Pero sí vamos a ver que para algunos de los personajes que estudiaremos la información es un poco más abundante y veremos como los dominios de varios de ellos se desenvolvían en un marco regional, no en

${ }^{7}$ C. ESTEPA, Las behetrías castellanas, Valladolid, 2003, t. 1, pp. 367-438, y t. 2, pp. 7-179.

${ }^{8}$ Por mi parte realicé algunas aproximaciones al estudio de la posición social y económica de la baja nobleza en I. ALVAREZ BORGE, Poder y relaciones sociales en Castilla en la Edad Media, Valladolid, 1996, pp. 152-172; también Nobleza y señoríos en Castilla la Vieja meridional a mediados del siglo XIV, "Brocar", 21 (1997), pp. 55-117. Entre otros trabajos a tener en cuenta merece citarse también T. SÁENZ DE HARO, Los Żapata (1148-1340), un ejemplo de aristocracia local en La Rioja Baja durante la Edad Media. en J.I. DE LA IGLESIA (coord.), Los espacios de

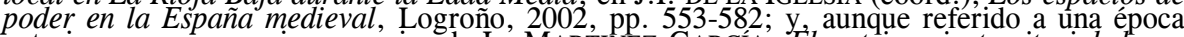
anterior y un personaje excepcional, L. MARTINEZ GARCIA, El patrimonio territorial de un miembro de la aristocracia feudal: Ródrigo Díaz, el Cid, en VV.AA., El Cid. Poema e Historia, Burgos, 2000, pp. 333-350. 
un ámbito local; para otros, sin embargo, creo que cabría hablar quizás de nobleza comarcal.

El grupo familiar está compuesto por los descendientes de Ordoño Pérez y Urraca Fernández. Durante la primera mitad del siglo XIII los bienes de los miembros de sus diversas ramas se extendían por las zonas próximas a Burgos y Villadiego, por la comarca de Muñó y por la ribera del Duero. El grupo familiar se documenta en 1194 cuando varios de sus miembros donaron al obispo de Burgos toda la heredad que tenían en Las Hormazas y que había sido de sus abuelos Ordoño Pérez y Urraca Fernández. Los donantes fueron Ordoño Pérez, Mencía con su marido Rodrigo, García Fernández, Vela García, Ordoño García, García García, Mayor García y Urraca García, abadesa del monasterio de Renuncio 9 . Todos ellos estaban emparentados entre sí como nietos de Ordoño y Urraca aunque no conocemos los vínculos exactos de parentesco.

(Véase Apéndice, cuadro 1).

\section{ORDOÑo PÉREZ I Y URRACA FERNÁNDEZ}

Sobre Ordoño Pérez I y su mujer nuestros datos son muy escasos. No conocemos su vinculación familiar con el linaje de Aza, que nos parece probable, pero sí sabemos que Ordoño fue mayordomo de García García (de Aza $)^{10}$. Probablemente, a este personaje se refiere también otro documento igualmente de 1194 por el cual sabemos que tuvo una serna cerca de San Pedro de Berlangas, entre la sede del monasterio y el río Arlanza; esa serna fue cedida al monasterio de Santa María de Valbuena en algún momento que desconozco y en 1194, como consecuencia de un pleito entre el obispo de Burgos y el abad de Valbuena, pasó a manos de la abadía de San Pedro de

${ }_{9}^{9}$ J.M. GARRIDO GARRIDO, Documentación de la Catedral de Burgos (1184-1222), Burgos, 1983 (= GARRIDO, Catedral de Burgos; también para J.M. GARRIDO GARRIDO, Documentación de la Catedral de Burgos (804-1183). Burgos, 1983), doc. 319. L. SERRANO indicó que pertenecían al linaje de Aza; véase El obispado de Burgos y la Castilla primitiva desde el siglo V al XIII, Madrid, 1935, t. 3, doc. 213; pero en todo caso se trataría de una rama secundaria porque, aunque fueran homónimos, no creo que ninguno de los que se mencionan aquí fuera hijo de García García de Aza; uno de ellos, García García de Roa, figura en la lista de testigos que se mencionan en el documento. Por otra parte, Serrano también indicó que la abadesa de Renuncio estaría emparentada con doña Elo, fundadora del monasterio de Valcárcel; Ibid., T. 2 , p. 302. Es probable que exista alguna relación, aunque no lo puedo señalar con seguridad. En cualquier caso, no se debe confundir a la mujer de Ordoño Pérez con la hija de Estefanía Armengol, también llamada Urraca Fernández; pero esta Urraca, tía de doña Elo, estuvo casada con un magnate leonés, Rodrigo Martínez y no consta un segundo matrimonio. Sobre Rodrigo Martínez y Urraca Fernández véase M. MANUECO VILLALOBOS y J. ZURITA NIETO, Documentos de la Iglesia de Santa María la Mayor de Valladolid. Siglos XI y XII, docs. XXVIII, XXX, XXXIII, XXXIV y XXXV; y P. MARTÍNEZ SOPENA, El conde Rodrigo de León y los suyos. Herencia y expectativa de poder entre los siglos X y XII, en R. PASTOR (Comp.), Relaciones de poder, de producción y de parentesco en la Edad Media y Moderna, Madrid, 1990, pp. $51-84$ especialmente pp. 71 y 73-74. Sobre los Aza en este período J. GoNZÁLEZ, El reino de Castilla en la época de Alfonso VIII, Madrid, 1960, t. 1, pp. 293-300.

${ }^{10}$ GARRIDO, Catedral de Burgos, doc. 153 de 1159. 
Berlangas, dependiente del obispo ${ }^{11}$. Ordoño Pérez y Urraca tuvieron también propiedades en Villaldemiro y en Arenas, que después heredó Vela García, su nieto mencionado en el documento de donación al obispo en $1194^{12}$. Igualmente, documentación posterior nos permite saber que tuvieron propiedades en zonas más alejadas, en Madrid y en Toledo, propiedades que veremos después en manos de sus nietos ${ }^{13}$. Por lo tanto, los datos disponibles sobre las propiedades de Ordoño Pérez I y Urraca Fernández son escasos, pero suficientes para señalar que sus intereses patrimoniales se extendían por zonas bastante distantes ${ }^{14}$.

\section{GARCÍA FERnÁNDEZ DE VILLAMAYOR}

Uno de los nietos de Ordoño Pérez I y Urraca Fernández mencionados en 1194 era García Fernández a quien pienso que se puede identificar sin dificultad con el personaje conocido como García Fernández de Villamayor. De todos los citados en el grupo de 1194 es el mejor conocido históricamente, el mejor documentado y también el que alcanzó una posición social y política más elevada. Su personalidad social y política fue objeto de dos estudios en las primeras décadas del siglo pasado por L. Serrano y recientemente he dedicado un artículo a repasar esos aspectos, centrándome en el acusado proceso de expansión patrimonial que realizó. Todo ello es posible por el apreciable rastro documental que se conserva, fundamentalmente en el monasterio cisterciense femenino de Santa María de Villamayor de los

${ }^{11}$ El obispo de Burgos, en representación dẹl monasterio de San Pedro de Berlangas, que le pertenecía, y el monasterio de Valbuena pleiteaban en torno a esa serna, que el obispo reclamaba a Valbuena, y a un molino y una pesquera en Talamanquilla. En 1194 acuerdan que San Pedro de Berlangas tendrá la serna y Valbuena el molino y la pesquera en Talamanquilla (quizás se refiera a Tălamanca, muy próxima a la zona del Arlanza donde estaban el monasterio de Berlangas y la serna en disputa); Ibid., doc. 315. En un primer momento en el documento se dice que la serna pertenecía a Ordoño Pérez y más adelante se indica que pertenecía a García Ordónez, quien qụizás fuera uno de los hijos de Ordoño Pérez. No he encontrado referencias a este documento ni al momento de adquisición de estas heredades en los estudios que conozco sobre el monasterio de Valbuena; véase V.A. ALVAREZ PALENZUELA, Monasterios cistercienses en Castilla (siglos XII-XIII), Valladolid, 1978, pp. 187-195; y M.J. O̊RTEGA GONZÁLEZ, Santa María de Valbuena. Un monasterio cisterciense a orillas del Duero (siglos XII-XV), Valladolid, 1983.

${ }^{12}$ Vela García y su mujer vendieron esas heredades a García Fernández de Villamayor en 1222; G. MARTínEZ y V. GONZÁLEZ, Colección diplomática. Monasterio cisterciense de Santa María La Real. Villamayor de los Montes, Burgos, 2000 (= MARTínEZ Y GoNZÁLEZ, Villamayor), doc. 20.

${ }^{13} \mathrm{Me}$ referiré más adelante con detalle a esas propiedades que finalmente acabaron en manos de la orden de Calatrava. Véase más abajo lo referido a Ordoño Pérez II de Cabia.

${ }^{14}$ De seguir la identificación propuesta por Serrano habría que considerar también el documento por el que Pedro Fernández con su esposa María Pérez y su hermana Urraca Fernández dan en 1165 al abad Miguel el monasterio de Santa Cruz de Valcárcel para que se establezca allí un monasterio de monjas o monjes de San Agustín; J.L. RODRÍGUEZ DE DIEGO, Colección diplomática de Santa Marịa de Aguilar de Campoo (852-1230), Valladolid, 2002 (= RODRÍGUEZ, A guilar), doc. 27; también L. SERRANO, Documentos del monasterio de Santa Cruz de Valcárcel, "Revista de Archivos Bibliotecas y Museos”, 12 (1905), pp. 115-127 y 240-252, y 13 (1905), pp. 118-126 ( = SERRANO, Valcárcel), doc. I. 
Montes, fundado por él y donde se conservan alrededor de 60 documentos directamente relacionados con él ${ }^{15}$.

García Fernández tuvo una carrera política destacada vinculado a los Girón y a la reina Berenguela, hija de Alfonso VIII de Castilla, esposa de Alfonso IX de León y madre de Fernando III. A lo largo de su vida fue mayordomo de la reina Leonor, esposa de Alfonso VIII, brevemente al final de su vida, después mayordomo también de la reina Berenguela y finalmente del propio rey Fernando III. También se ocupó de la crianza del infante y futuro rey Alfonso X. Su posición política le permitió situarse entre las filas de la alta nobleza, una posición que heredarían tras él algunos de sus numerosos hijos, sobre todo Juan García. Esa posición política le permitió también, según he mostrado con detalle en el artículo mencionado, llevar a cabo un proceso de expansión patrimonial muy intenso en las merindades de Castrojeriz, Muñó, Silos, Cerrato y Monzón, especialmente en las zonas de Muñó y Lerma. Realizó ese proceso desarrollando una acusada política de compras de heredades y entre esas compras destacan por su número e intensidad las que tuvieron como vendedores a diversos parientes. Algunos de ellos figuran también en el grupo de los nietos de Ordoño Pérez y Urraca Fernández, según veremos con detalle en las páginas siguientes. Unas relaciones de parentesco entre García Fernández y los demás del grupo de 1194 cuya naturaleza exacta desconocemos, más allá de su condición común de nietos de Ordoño Pérez y Urraca Fernández; pero que se documentan también por la frecuencia con que unos u otros aparecen en las compraventas realizadas por García Fernández, sea como vendedores, fiadores o testigos.

\section{ORDOÑO PÉREZ II DE CABIA Y SUS DESCENDIENTES}

Pero el primero de los donantes citados en 1194 es Ordoño Pérez, homónimo del antepasado común a todos ellos, que aparece documentado como Ordoño Pérez de Cabia o de Quintanilla y a quien llamaré Ordoño Pérez II para distinguirlo de su abuelo. Su padre era Pedro Ruiz o Rodríguez, que en algún texto figura con el apelativo mio Cid, y de él conocemos que tuvo propiedades en Cabia y en Vivar, junto a la ciudad de Burgos, y en zonas de Madrid y de Toledo (mapa 1). En Cabia, Pedro Rodríguez vendió un solar a

${ }^{15} \mathrm{~L}$. SERrANo, El ayo de Alfonso el Sabio, "Boletín de la Academia de la Lengua Española”, VII (1920), pp. 571-602; L. SERRANO, El mayordomo mayor de, doña Berenguela, "Boletín de' la Real Academia de la Historia”, CIV'(1934), pp. 101-198; e I. ALVAREZ BORGE, Los dominios de un noble de la corte castellana en la primera mitad del siglo XIII. García Fernández de Villamayor, "Hispania", 230 (2008), pp. 647-706. Véase también MARTínEZ Y GONZÁLEZ, Villamayor; también VV'. AA., Jornadas culturales con motivo del IX Centenario de la fundación del Císter, Burgos, 1998, especialmente el artículo de G. MARTínEZ, El linaje de los Villamayor, en pp. 133-170. Puesto que es el mejor conocido de todos los nietos de Ordoño Pérez y Urraca Fernández será a quien dedique menos atención aquí, remitiendo a los trabajos mencionados. 
Martín en $1159^{16}$. En cuanto a las heredades de Vivar, a propósito de ellas conocemos su relación de parentesco con Ordoño Pérez II de Cabia. También en 1194 y en un acto jurídico que sin duda está relacionado con la donación de los nietos de Ordoño Pérez I al obispo, Ordoño Pérez II y su hermana Inés vendieron igualmente al obispo las heredades que tenían en Vivar procedentes de la herencia de su padre Pedro Rodríguez; el fiador fue el propio Ordoño Pérez II quien obligó como fiaduría todas sus heredades en Cabia ${ }^{17}$. Esta venta ha quedado registrada también en otro texto; se trata de un documento sin fecha que indica que el obispo de Burgos Martín (1181-1200) donó al cabildo varias heredades, entre ellas dedit hereditatem qua ipse emit in Uiuar de Ordonio Petri de Cauia. Iste vero qui uendidit loco fideiussoris obligauit totam hereditatem suam que habet in Cauia ${ }^{18}$. No hay duda, por lo tanto, que se trata de las mismas heredades a que hace referencia el documento de 1194. El documento de la venta de 1194 nos ofrece valiosa información sobre el parentesco de Ordoño Pérez II al indicarnos que su padre era Pedro Rodríguez y que su hermana se llamaba Inés. Ademas, en él figuran también como testigos otros parientes, como García Ordóñez, hijo de Ordoño García, mencionado también en el grupo de nietos de Ordoño Pérez I en 1194. Gonzalo Gómez, hijo de Gómez García, otro testigo, también podría pertenecer al mismo grupo de parientes. Por otros documentos, a los que me referiré más adelante, sabemos que la madre de Ordoño Pérez II se llamaba también Inés.

Las propiedades de Vivar, llamado también Quintanilla Morocisla llevan a pensar que Ordoño Pérez de Cabia es el mismo personaje que aparece también como Ordoño Pérez de Quintanilla ${ }^{19}$. Estaba casado en primer matrimonio con Sancha Ruiz, hija de Rodrigo González, y una hija suya se llamaba Inés (como su tía y su abuela) y estaba casada con Bueso. Este último pertenecía al grupo familiar del que descienden los Girón y me pregunto si Rodrigo González, el padre de Sancha Ruiz, no pertenecería también a la familia Girón ${ }^{20}$.

${ }^{16}$ J.M. LIZOAIN GARRIDO, Documentación del monasterio de Las Huelgas de Burgos (11161230). Burgos, 1985 (= LIZOAIN, Huelgas; también para J.M. LIZOAIN GARRIDO, Documentación del monasterio de Las Huelgas de Burgos (1231-1262), Burgos, 1985; y J.M. LizOAIN GARRIDO, Documentación del monasterio de Las Huelgas de Burgos (1263-1283). Indices (11161283), Burgos, 1987), doc. 2.

${ }^{17}$ Ibid., doc. 320.

${ }^{18} \mathrm{Ibid}$., doc. 218. Su editor ha fechado el documento entre 1181 y 1200 atendiendo al episcopado de Martín o Marino pero, dado que la compra de las heredades de Vivar se puede fechar en 1194, hay que datar la donación al cabildo entre esa fecha y el final de su episcopado en 1200 . 317-318

${ }^{19} \mathrm{Ya}$ lo propuso en su día SerRano en El obispado de Burgos, t. 3, doc. 202, nota 2 en pp.

${ }^{20}$ Bueso no es un nombre frecuente y por ello el riesgo de homonimia es menor que en otros casos. Era el nombre de un merino regio en Carrión y Saldaña al final del reinado de Alfonso VII y a comienzos de la década de los 60 que estaba casado con Urraca Pérez; era hijo de Diego Muñoz, esposo de Urraca Téllez, hija de Tello Fernández de quien descienden los Girón. El Bueso que nos interesa aquí ha de ser otro personaje distinto pero muy probablemente emparentado con él, quizás sea su hijo o su nieto. Sobre los Girón y el merino del emperador GoNZÁLEZ, Alfonso VIIII, T. 1, pp. 352-363; J. GonZÁLEZ, Reinado y diplomas de Fernando III, Córdoba, 1980-1983, T. 1, pp. 156-161; BARÓN, Grupos y dominios aristocráticos, pp. 263-266; 
Sancha Ruiz también se documenta como propietaria en Quintanilla Morocisla, donde tenía heredades que donó al obispo de Burgos en diciembre de 1190, aunque siguió conservando algunos derechos en el lugar, puesto que retuvo para sí una divisa. Esa donación fue corroborada por su hija Inés y por Bueso quienes, además, en esa misma fecha también vendieron al cabildo sus heredades en Quintanilla Morocisla ${ }^{21}$. Sin embargo Sancha Ruiz y Ordoño Pérez II todavía conservaron algunas heredades en la villa puesto que en noviembre de 1194 hicieron un cambio con García, al que entregaron un tierra a cambio también de una pasada de tierra en el cementerio de Santa Eulalia y 7 maravedís 22 .

Sancha Ruiz fue la primera esposa de Ordoño Pérez II y se documenta como tal en 1194; pero debió morir poco después, puesto que en 1201 ya aparece casado con su segunda esposa María Gutiérrez. Como he señalado más arriba, Ordoño Pérez I y su esposa Urraca Fernández tuvieron heredades en zonas de Madrid y de Toledo, que después pasaron a sus hijos y tras ellos a sus nietos. Ordoño Pérez II heredó parte de esas propiedades y, casado ya con su segunda esposa María Gutiérrez, compró otras a sus primos - hijos de su tía Elo y de Lope Díaz-, para después vender todas ellas a la orden de Calatrava. Se trata de unas casas en Madrid en el barrio de Santa María, heredades en Valnegral que era una aldea de Madrid, y heredades en otras dos aldeas de Toledo: Moratalaz y Otos.

En 1201 Rodrigo López, por un lado, y Álvaro López y Urraca López, por otro, vendieron a Ordoño Pérez y su esposa María Gutiérrez sus heredades en esos lugares por 25 y 50 maravedís respectivamente ${ }^{23}$. El precio nos da idea de que se trata de partes equivalentes de una herencia común. En efecto, el bloque originario de bienes de sus abuelos se había dividido en cuatro partes, presumiblemente una para cada uno de sus hijos; una de ellas habría correspondido a Pedro Ruiz y su esposa Inés y a través suyo recibió la parte correspondiente Ordoño Pérez II; otra parte correspondería a Elo y su esposo Lope Díaz y de ellos pasó a sus cuatro hijos: Rodrigo López, Álvaro

y C. ESTEPA, Sobre los orígenes de los merinos mayores en Léon y Castilla, en J.M. MínGUEZ y G. DEL SER (coords.), La Península en la Edad Media treinta años después. Estudios dedicados a José Luis Martín, Sạlamanca, 2006, pp. 87-100. La vinculación con los Girón también se puede ver en otros de los nietos de Ordoño Pérez I y Urraca Fernández, como es el caso de García Fernández (de Villamayor); véase AlVAREZ BORGE, Los dominios de un noble de la corte.

${ }^{21}$ GARRIDO, Catedral de Burgos, docs. 294 y 295. Tanto la donación de Sancha Ruiz como la venta de doña Inés y don Bueso están fechadas en diciembre de 1190, lo que evidencia que se trata de dos cesiones relacionadas entre sí. Las listas de testigos de ambos documentos también son muy similares, aunque con ligeras variaciones en el orden en que se citan algunos personajes; en ambas figura Ordoño Perez de Quintanilla.

${ }^{22}$ Ibid., doc. 325. La identificación del cementerio en el lugar de Quintanilla Morocisla en J.M. LIZOAIN GARRIDO y J.J. GARCÍA GONZÁLEZ, El monasterio de Las Huelgas. Historia de un monasterio cisterciense burgalés (siglos XII y XIII), Burgos, 1988, p. 137.

${ }^{23}$ E. RoDRÍGUEZ-PICAVEA, Documentos para el estudio de la orden de Calatrava en la meseta meridional castellana (1102-1302), "Cuadernos de Historia Medieval", Sección Colecciones Documentales, 2, 1999 (edición electrónica) (= RoDRÍGUEZ-PICAVEA, Calatrava), docs. 125 y 631, donde publica los regestos de los documentos; el texto completo en AHN, OO. MM, Calatrava, carp. 456, n ${ }^{\circ} 45$, para la venta de Rodrigo López, puesto que la de Alvaro y Urraca López sólo se conserva en la copia realizada en el Registro de escrituras de la Orden de Calatrava, t. II, fol. 6, en AHN, OO. MM., Calatrava, Libros manuscritos, sign. 1342; aquí mismo en el fol. 3 se copio también la venta de Rodrigo López. 
López, Urraca López y Gutierre López. Su primo Ordoño Pérez II adquirió en 1201 la parte correspondiente a los tres primeros, según se recoge en estos documentos que se han conservado, pero otro texto informa de que también adquirió la parte del cuarto de sus primos citados ${ }^{24}$. Pocos años después, en 1206 Ordoño Pérez II vendió a la orden de Calatrava todos los bienes que poseía en esos lugares por 230 maravedís, señalando que se trata de la cuarta parte de los que tuvieron sus abuelos Ordoño Pérez I y Urraca Fernández y que se trata de bienes adquiridos a sus primos mencionados. Aunque han pasado cinco años desde que comprara esos bienes a sus primos, el precio recibido ahora no se corresponde con el pagado entonces -25 maravedís por cada cuarto-

De esta importante venta realizada en el mes de marzo se conservan varias copias, además del documento original, que añaden más información relativa a las relaciones familiares ${ }^{25}$. En una de ellas se dice que este uendedor don Ordon Pedrez es el de Cabia, filio de mio Cid Pedro Ruiz. Un mes más tarde, se realizó otro documento en el que Ordoño Pérez reconocía la venta anterior; la información es la misma en lo fundamental y también otorga la venta su esposa María Gutiérrez, pero ahora se indica que su esposa era hija de Gutierre Díaz. Aunque no se ofrecen más datos sobre ese Gutierre Díaz, el primer testigo del documento es un miembro del grupo familiar de los Sandoval -lamentablemente su nombre no se ha conservado en la copia disponible, pero sí el apellido identificador-; de manera que considero que hay bases suficientes para pensar que podría tratarse de Gutierre Díaz de Sandoval, que había sido merino mayor de Castilla entre 1198 y $1205^{26}$. Importa aclarar en lo posible los orígenes familiares de su esposa para valorar el círculo de relaciones internobiliarias en que se desenvolvía Ordoño Pérez II de Cabia. Años más tarde, ya en 1220, se documentan de nuevo las propiedades de Ordoño Pérez en Madrid, cuando el maestre de Calatrava cede a don Moriel Ibáñez y a su esposa las casas que habían sido de Ordoño Pérez en Madrid a cambio de otras en el mismo lugar ${ }^{27}$.

En los textos mencionados, Ordoño Pérez II, además de vender sus bienes, otorga también la venta que su madre Inés había hecho a la misma orden de su parte en los mismos lugares. No se conserva ningún documento

\footnotetext{
${ }^{24} \mathrm{AHN}, \mathrm{OO} . \mathrm{MM}$, Calatrava, carp. 456, $\mathrm{n}^{0} 45 ;$ y Registro de escrituras de la Orden de Calatrava, T. II, fol. 6 .

${ }^{25}$ EODRÍGUEZ-PICAVEA, Calatrava, doc. 138; y el original en AHN, OO. MM, Calatrava, carp. 457, $\mathrm{n}^{\mathrm{O}} 59$. De este documento se realizó después, también en pergamino, un testimonio en el que se añadieron nuevos datos de utilidad para la orden: RODRÍGUEZ-PICAVEA, Calatrava, doc. 137; y el original en AHN, OO. MM, Calatrava, carp. 457, n ${ }^{\circ}$ 58. Ambos, original y testimonio fueron copiados más tarde en el Registro de escrituras de la Orden de Calatrava, T. II, fols. 20 y 21 , el copista añadió entonces al margen un árbol genealógico de todos estos personajes.

${ }^{26}$ RodRíGUEZ-PICAVEA, Calatrava, doc. 139; y. Registro de escrituras de la Orden de Calatrava T. II, fol 22. Se señala también aquí la filiación de Ordoño Pérez como hijo de "Pedro Roiz mio Cid". Sobre el merino Gutierre Díaz de Sandoval, GonZÁLEZ, Alfonso VIII, t. 1, pp. 245-248. Sobre los Sandoval, que se incluyen en el ámbito de los caballeros de la nobleza regional, véase ESTEPA, Las behetrías castellanas, t. 1, pp. 396-401.

${ }^{27}$ RodríGUEZ-PICAVEA, Calatrava, doc. 170; AHN, OO.MM, Calatrava, carp. 458, $\mathrm{n}^{\mathrm{o}} 83$; y Registro de escrituras de la Orden de Calatrava, t. II, fol 110.
} 
que recoja esa venta, pero sí otro que contiene la venta realizada en 1202 por Inés y su hermana María, ambas religiosas e identificadas como hijas de Ordoño Pérez, en favor de la orden de Calatrava de sus bienes en Toledo, Algorfiella (Algurilla en Fuensalida, Toledo) y otros lugares ${ }^{28}$. Dada la frecuencia del nombre de Inés entre las mujeres de la familia, Inés y María podrían ser hermanas o hijas de Ordoño Pérez II.

Las últimas referencias a propiedades de Ordoño Pérez II proceden de nuevo de zonas de Castilla al norte del Duero. Sabemos que tuvo heredades en Espinosa de Cervera, en el alto Esgueva, que se documentan al ser citadas entre los límites de otras que tenía Ordoño García de Castil Sarracín y que este vendió al monasterio de Silos en $1222^{29}$. También se conocen otras propiedades más al norte, cerca de Aguilar de Campoo, en Cillamayor y en Canduela; propiedades que heredó de su abuela Urraca Fernández y que vendió en 1216 a Teresa Vermúdez por 50 maravedís ${ }^{30}$. Este, además, es el último documento que se refiere a él directamente.

(Véase Apéndice, cuadro 2).

El nombre de Ordoño Pérez no es infrecuente y no es fácil distinguir entre todos los personajes homónimos. Además, como veremos más adelante, Ordoño Pérez II tenía un nieto con el mismo nombre y algunas referencias pueden atribuirse a uno u otro. En los años 20 del siglo XIII el monasterio de Las Huelgas compró y cambió varias tierras en Quintanilla Morocisla y en los documentos que recogen esas compras suele aparecer con cierta frecuencia como confirmante y a veces como vendedor un personaje llamado Ordoño de Quintanilla, que en ocasiones se identifica como caballero o como escudero, pero no creo que se corresponda con el mismo personaje a que me refiero; quizás, si es que todas las referencias corresponden a un único individuo, pueda tratarse de alguno de sus descendientes ${ }^{11}$. También me parece dudosa la posible identificación con otro Ordoño Pérez, propietario destacado en Valdetobes, al norte de Burgos, documentado entre 1181 y $1185^{32}$. Por último, también se documenta un Ordoño Pérez de Pardilla, casado con

\footnotetext{
${ }^{28}$ RodRíGUEZ-PICAVEA, Calatrava, doc. 126, donde se señala que el documento orginal - que no he consultado- fue redactado en árabe; véase AHN, OO.MM, Calatrava, carp. 471, no 415.

${ }^{29} \mathrm{El}$ vendedor era otro pariente, citado en 1994 en el grupo de los nietos de Ordoño Pérez I, como veremos. M.C. VIVANCOS GÓMEZ, Documentación del monasterio de Santo Domingo de Silos (954-1254), Burgos, 1988 (= VIVANCOS, Silos), doc. 104.

${ }^{30}$ RodríGUEZ, Aguilar, doc. 271.

${ }^{31}$ Ya en 1187 figura un Ordoño Pérez, hijo de Pedro González de Quintanilla como testigo en una venta en otro lugar y en un contexto que me llevaría a pensar que se trata de un campesino y probablemente en referencia a algún otro de los lugares llamados Quintanilla; GARRIDO, Catedral de Burgos, doc. 275. En 1204 don Armengol (de la familia de los condes de Urgell, hijo de María Almenara y Lope López de Haro) empeño la heredad que tenía en Palazuelos de Lara durante un año y por 800 maravedís a Pedro Martínez de Arconada, portero de la reina Leonor; el último de los testigos que figuran en el documento correspondiente fue don Ordoño de Quintanilla: LizOAIN, Huelgas, doc. 77. Las restantes referencias son unos años más tarde, entre 1219 y 1237 , de manera que no estoy seguro de que la de 1204 y las siguientes correspondan al mismo individuo (quizás el de 1204 se corresponda con Ordoño Pérez II). Las referencias en Ibid., docs. 139, 157, 161, 170, 192, 196, 199, 200 y 297.

${ }^{32}$ GARrido, Catedral de Burgos, docs. 212, 217, 227, 247 y 253.
} 
Urraca Rodríguez y con propiedades destacables en villas al sur del Duero en las zonas de Roa y de Montejo (mapa 1). Son zonas en las que también tendrán heredades otros descendientes de Ordoño Pérez I y a algunos de ellos los vemos también en relación con Ordoño Pérez de Pardilla; de manera que creo que estaba emparentado con ellos, aunque desconozco la vinculación exacta $^{33}$.

En todo caso, Ordoño Pérez II de Cabia, hijo de Pedro Rodríguez y nieto de Ordoño Pérez I, tuvo propiedades al menos en Cabia, Quintanilla Morocisla o Vivar, Espinosa de Cervera, Cillamayor y Canduela en Castilla al norte del Duero, y otras en Madrid, Valnegral, Otos y Moratalaz en la zona del Tajo; propiedades, por tanto, al menos, al norte de la actual provincia de Palencia, en la zona entorno a Burgos, en la zona del Esgueva, en Madrid y en Toledo. De manera que, aunque el número de lugares donde conocemos propiedades de Ordoño Pérez II, con cierta seguridad, no parezca muy elevado, hay que tener en cuenta el carácter muy fragmentado de la documentación conservada y, por el contrario, el radio de acción de sus intereses patrimoniales nos habla de una amplia proyección.

Están documentados como hijos de Ordoño Pérez II, Pedro Ordóñez, Inés y Mayor Ordóñez, probablemente también fue hija suya Teresa Ordóñez y quizás también María.

El primero es citado como fiio de Ordon Pedrez de Cauia en 1224 y se documenta como propietario de heredades en Villamayor de los Montes y en Gumiel de Izán. Ambas las vendió a su pariente García Fernández (de Villamayor) y ambas en 1232, en dos operaciones diferentes aunque realizadas

${ }^{33}$ En 1231 se menciona a Ordoño Pérez y a su mujer Urraca Rọríguez en la confirmación realizada por Fernando III de un convenio entre ellos y el monasterio de San Pedro de Gumiel: Ordoño Pérez y su mujer entregaban al monasterio sus heredades de Montejo y el monasterio les cedía por su vida las heredades recibidas, la "casa" de Anaya Alfonso con nueve yuntas de bueyes, aceñas, molinos y viñas, la "casa" de Gumiel con dos yuntas de bueyes y las rentas de los collazos que el monasterio había comprado a Vela García, y dos cubas de vino anuales; GonZÁLEZ, Fernando III, T. 2, doc. 369; también ALVAREZ PALENZUELA, Monasterios cistercienses, p. 225 nota 346 y p. 226 nota 355 ; y para el texto completo, AHN, Clero, Pergaminos, carp. 231, $\mathrm{n}^{\mathrm{O}} 7$. Entre 1242 y 1246 se desarrolla un pleito entre los monasterios de La Vid y de Gumiel sobre sus propiedades y derechos en varias villas; de dos de ellas, Santa Cruz y Tamarón, situadas al sur del Duero en la zona de Montejo, se dice que habían sido de Ordoño Pérez de Pardilla y que el monasterio de La Vid posee el ius sobre ellas (ius dicimus nos debere habere); la sentencia dictada por el obispo de Burgos da la razon al monasterio de La Vid en este punto; ẢHN, Clero, Pergaminos, carp. 380, n ${ }^{\circ} 7$; e Indice de los documentos procedentes de los monasterios y conventos suprimidos que se conservan en el archivo de la Real Academia de la Historia. Sección Primera. Castilla y León, t. 1 (Monasterios de Nuestra Señora de La Vid y San Millán de la Cogolla), Madrid, 1861 (=Indice... La Vid), doc. 147 pp. 149-150. Ordoño Pérez y su hermana Milia tuvieron también heredades en Fuentenebro y Torregalindo en la zona de Aza, que vendieron a García Ordóñez y después sus herederos, las entregaron al monasterio de La Vid en 1226; AHN, Clero, Pergaminos, carp. 380, n ${ }^{\circ}$; e Indice... La Vid, doc. 146, p. 148. Esta último documento (el primero de esta serie desde el punto de vista cronológico) puede referirse también a Ordoño Pérez de Pardilla porque se refiere a las mismas zonas que los anteriores y porque uno de los testigos del documento es Ordoño Pérez, hijo de Pedro Pardilla; sin embargo, no estoy completamente seguro de que esta referencia no corresponda a Ordoño Pérez II, pariente de García Ordóñez.

Conviene señalar que alguos caballeros llamados Ordoño Pérez recibieron heredades en el Repartimiento de Sevilla, pero me resulta imposible determinar si se trata de alguno de los mencionados más arriba e incluso si se trata de un único individuo o de varios homónimos. J. GonZÁlEZ, Repartimiento de Sevilla, t. 2, Madrid, 1951, pp. 64, 225 y 239. 
en un plazo de muy pocos días ${ }^{34}$. El último de los testigos hidalgos citados en el documento que recoge la venta de las heredades de Gumiel de Izán es Ordoño Pérez ${ }^{35}$. Creo que debe tratarse de Ordoño Pérez III, muy probablemente hijo de Pedro Ordóñez, y homónimo de su abuelo Ordoño Pérez II y de su trasabuelo Ordoño Pérez I.

En realidad, como señalaré más adelante, no documentamos a Ordoño Pérez III como hijo de Pedro Ordóñez, sino como sobrino de Mayor Ordóñez, de quien sí consta que era hija de Ordoño Pérez II y, por lo tanto, hermana de Pedro; la sucesión de los apellidos me lleva a considerar Ordoño Pérez hijo de Pedro Ordóñez. Por otro lado, la documentación no ofrece suficientes garantías de que todas las referencias a Ordoño Pérez correspondan al mismo personaje, ni que todas se refieran a Ordoño Pérez III. Incluso, como ya he señalado, dudo si en algunas ocasiones no podría tratarse de su abuelo Ordoño Pérez II. Los datos disponibles sobre su patrimonio son escasos; se limitan a constatar sus propiedades en Cabia, propiedades que se documentan años después al citarse entre los límites de otras que adquirió el monasterio de Las Huelgas $^{36}$. También sabemos que tenía propiedades en Las Grajeras y en Villadiego y en otros lugares sin especificar, que en 1243 tenía empeñadas su tía Mayor Ordóñez ${ }^{37}$. Pero la primera referencia documental que quizás podría atribuírsele podría ser de 1228. En ese año su pariente García Fernández (de Villamayor) y su mujer Mayor Arias adscribían su monasterio de Santa María a la orden del Císter y lo ponían bajo la autoridad de la abadesa del monasterio de Las Huelgas de Burgos. Es, evidentemente, un documento importante en el que figuran un buen número de testigos: varios eclesiásticos, los hijos y otros parientes de García Fernández, otros nobles de la zona, etc.; y uno de los testigos es Ordoño Pérez. Tiendo a pensar que puede tratarse de Ordoño Pérez III, aunque quizás sería más lógica la presencia de su padre Pedro Ordóñez; pero tampoco creo que pueda descartarse que se trate de su abuelo Ordoño Pérez II, aunque su última referencia documental directa sería de $1216^{38}$. Con mayor probabilidad puede pensarse que Ordoño Pérez III figuró también como testigo en otros documentos que recogen otras tantas adquisiciones de heredades por García Fernández en los años siguientes. En 1231 cuando las hermanas Toda y Urraca Fernández con sus respectivos maridos le vendieron las heredades que tenían en Quintanilla de Valdado; y en 1234 cuando los coherederos renuncian a la herencia que les correspondería de Ruy

${ }^{34}$ GONZÁLEZ, Fernando III, t. 2, doc. 200, aunque con importantes lagunas respecto al original en AHN, Clero, Pergaminos, carp. 380, n⿳2 2; e Indice. La Vid, doc. 17, pp. 15-16. Y las ventas a García Fernánđez en MARTínEZ y GonZÁLEZ, Villamayor, docs. 39 y 40.

${ }^{35}$ Interesa señalar también que Pedro Ordóñez de Cabia fue testigo en otra venta realizada ese mismo año por Gil Gílez de Osorno a García Fernández y su mujer de sus heredades en Villovela; a su vez, Gil Gílez fue testigo en la venta de Pedro Ordóñez de las heredades de Villamayor;
Ibid., doc. 41 .

${ }^{36}$ LizOAIN, Huelgas, doc. 548 de 1266.

${ }^{37}$ Ibid., doc. 337 .

${ }^{38}$ MARTíneZ y GonZÁLEZ, Villamayor, doc. 29. 
Pérez entregando sus bienes a García Fernández en reconocimiento de las deudas que Ruy Pérez tenía contraídas con él ${ }^{39}$.

Otra de las hijas de Ordoño Pérez II fue Mayor Ordóñez. Sólo se conserva un único documento relacionado con Mayor, pero es muy interesante. Se trata de su testamento, que realizó en 1243 encontrándose enferma y solicitando ingresar en el monasterio de Las Huelgas de Burgos, en cuyo archivo se ha conservado ${ }^{40}$. La información que proporciona el testamento es abundante y merece un análisis detenido. Un primer dato interesante es que Mayor Ordóñez vivía en Grajera (Las Grajeras en el documento), actualmente un despoblado no lejos de Castrojeriz, al noreste, entre Villandiego y Olmillos de Sasamón. El testamento no ofrece muchos datos sobre los vínculos de parentesco de Mayor, pero sí se citan dos sobrinos: el ya mencionado Ordoño Pérez III y Diego López, hijo de Lope Álvarez. Este Lope Álvarez es Lope Álvarez de Grajera, casado con Teresa Ordóñez a quien considero hermana de Mayor. Por lo tanto, parece que Mayor vive en un lugar, Grajera, que es el centro de referencia de la familia de su cuñado, otra familia de nobles locales a los que me referiré más adelante. No se mencionan hijos ni esposo de Mayor y hay que pensar que o no los tuvo o no le sobrevivieron.

El principal beneficiario del testamento fue el monasterio de Las Huelgas de Burgos, donde ordenó ser enterrada y al que dejó todas las heredades que tenía en Cabia, una mula y 50 maravedís. En el testamento se especifica que esos 50 maravedís corresponden a una deuda que su sobrino Ordoño Pérez tenía con ella por haberle empeñado todas sus heredades en Grajera y en tierra de Uilladiago, heredades que Mayor entrega al monasterio hasta que su sobrino salde su deuda. Además de lo que dejó al monasterio de Las Huelgas, Mayor estableció diversas mandas por un monto total de 841 maravedís y 14 almudes de trigo; aunque una suma al final del documento indica que el total de las mandas alcanzaría 891 maravedís y 14 almudes de trigo, mientras que las deudas sumaban 39 maravedís menos tercia y 41 almudes de trigo. Las mandas se refieren a un total de 10 individuos y 6 instituciones religiosas, además del citado monasterio de Las Huelgas. A la cabeza de estas últimas estaba el monasterio de Renuncio, al que dejó 200 maravedís, y al que ya vimos vinculado a su familia en tiempos anteriores (recordemos que en 1194 la abadesa de ese monasterio era Urraca García, nieta de Ordoño Pérez I). Se señalan también 8 maravedís para los descalços de Castro y 5 maravedís para otras 4 instituciones para celebración de sendos

\footnotetext{
${ }^{39} \mathrm{Ibid}$. docs. 36 y 48 . Recuérdese que también figura como testigo cuando su padre vendió a García Fernández sus heredadẹs en Gumiel de Izán en 1232; Ibid., doc. 40. Otra referencia de esos mismos años puede considerarse dudosa. En 1232 Giil Pẻrez de Marañón vendió al monasterio de Gumiel lo que tenía en la villa de Vadocondes, reconociendo al monasterio que lo tenía por la fuerza ("forciada") y ordena a su caballero Ordoño Pérez que ponga al monasterio en posesión de esos bienes y derechos. Creo que puede tratarse de Ordoño Pérez III que, de esa manera, aparecería vinculado a un noble de posición superior; pero en el documento figura también como testigo un Ordoño Pérez de Revilla, lo que me genera algunas dudas sobre su identidad. C. de AYALA (ed.), Libro de privilegios de la orden de San Juan de Jerusalén en Castilla y León (siglos XII-XVi), Madrid, 1995 (ÂYAA, San Juan), doc. 258.

${ }^{40}$ LizOAIN, Huelgas, doc. 337. Sobre este texto también ÁlvarEZ BORGE, Poder y relaciones sociales en Castilla, p. 152.
} 
aniversarios: los clérigos de Grajera, las cofradías de Villadiego y de Boada y el monasterio de Valcárcel. Las mandas a los laicos están encabezadas por su sobrino Diego López, al que deja 500 maravedís en desagravio, porque tof grant tiempo so heredamiento e non le di nada nin ninguna cosa dello. Y, junto a él, cantidades menores para otras personas, quizás algunos parientes cuyos vínculos con Mayor desconocemos y algunos criados.

Así pues, en total algo menos de 900 maravedís y 14 almudes de trigo que se pueden comparar con los más de 6.000 maravedís y diversas joyas que se mencionan en el testamento de García Fernández (de Villamayor) realizado posiblemente en esas mismas hechas, en 1240 ó $1241^{41}$. Las cifras de uno y de otra dan cuenta gráficamente de los distintos niveles dentro de la nobleza.

Para ejecutar su testamento, Mayor nombró a sus cabezaleros y estableció que pudieran disponer de sus heredades para cumplir las mandas. A ese fin señaló todos los lugares donde poseía heredades. Es una información muy valiosa que nos permite apreciar el conjunto del dominio de Mayor. En total sus bienes se extendían por 12 villas situadas en su mayoría en la zona de la merindad de Villadiego (mapa 1).

Aunque el testamento de Mayor no es muy rico en datos de parentesco, sí ofrece alguna información que permite avanzar en la reconstrucción de los descendientes de Ordoño Pérez II. Como hemos visto, se menciona a dos sobrinos: Ordoño Pérez y Diego López. El primero es Ordoño Pérez III, hijo de Pedro Ordóñez, a quien ya me he referido. El testamento indica que tenía otros hermanos, aunque no señala sus nombres, puesto que uno de los testigos labradores es Domingo Perez, merino de fiios de Pedro Ordonez. El otro sobrino es Diego López, quien también figura como testigo, identificándose como hijo de Lope Âlvarez, entre los testigos hidalgos. Por otros documentos que citaré enseguida sabemos que su madre era Teresa Ordóñez y que, al menos, tenía otros dos hermanos llamados Ruy López y, significativamente, Ordoño López.

Hay, por lo tanto, una alianza por vía matrimonial entre estas dos familias de la baja nobleza, los Cabia y los Grajera. Pero es una alianza que se retrotrae al menos unos años más atrás. En 1203 tuvo lugar un pleito entre el monasterio de San Cristóbal de Ibeas de Juarros y Lope Alvarez. Lamentablemente de esos hechos sólo se ha conservado una noticia, no el documento de referencia completo, por lo que nuestra información es deficiente, pero creo que es probable que ese Lope Álvarez se corresponda con Lope Álvarez de Grajera. En el contexto del pleito, que fue juzgado por el conde Fernando de Lara y por Gonzalo Pérez de Torquemada por orden del rey, el noble y el monasterio pusieron fideles y ambas partes conjuntamente dieron como superfidele a Ordoño Pérez (II) de Cabia ${ }^{42}$.

\footnotetext{
${ }^{41}$ MARTínez y GonZÁlez, Villamayor, doc. 50; y Álvarez Borge, Los dominios de un noble de la corte.

${ }^{42}$ G. MARTínez DíEZ, Colección diplomática burgalesa, I. Diplomatario de San Cristobal de Ibeas "Boletín de la Institución Fernan González", 185 (1975), pp. 689-720 (= MARTínEZ, Ibeas), doc. 35 .
} 
Lope Álvarez no es el único noble que se identifica con el apellido de Grajera por esos años. Por entonces se documentan también Diego García de Grajera, Gonzalo García de Grajera y Fernando Ruiz de Grajera. Es probable, aunque no lo he podido verificar documentalmente, que fueran parientes entre sí (parece probable que Diego García y Gonzalo García fueran hermanos) y también de Lope Álvarez. Sea como fuere, también aparecen relacionados con Ordoño Pérez (II) de Cabia y con sus parientes García Fernández (de Villamayor) y Vela García (los tres nietos de Ordoño Pérez I ${ }^{43}$.

Además de Grajera, donde no se documentan pero parece probable que tuvieran heredades, constan propiedades de los hijos de Lope Álvarez en Los Valcárceres, al noreste de Burgos, no lejos de Villadiego, y en Villamórico, al oeste de Burgos, cerca de Arlanzón y de Ibeas de Juarros (recuérdese el pleito de su padre con el monasterio de Ibeas). Por lo tanto, pocos lugares documentados, pero en zonas relativamente distantes. Quizás en 1244 Ruy López y su hermano Diego López, identificándose como hijos de Lope Álvarez y Teresa Ordóñez, vendieron al monasterio de Santa Cruz de Valcárcel todas sus propiedades en Los Valcárceres por 370 maravedís ${ }^{44}$. Poco después, en 1249 Ruy López, identificándose como hijo de Lope Álvarez de Grajera, vendía a Ponz del Vals y a sus hermanos, ciudadanos burgaleses, dos partes de lo que poseía conjuntamente con su hermano en Villamórico por 40 maravedís y un manto en robra. Señaló que las dos partes que vendía eran la suya y la de otro hermano llamado Ordoño López que ya había muerto ${ }^{45}$.

Hay otros personajes que probablemente estaban emparentados con estos, aunque no se puede afirmar con exactitud. Así, ya en 1172 se menciona a un Pedro Pérez de Cabia que fue testigo cuando María Almenar, hija del conde Armengol de Urgell, dio a la orden de Calatrava todo lo que tenía en Talavera. Más adelante, en 1234, Pedro Ruiz de Cauiola (Cayuela, junto a Cabia) vendió también a García Fernández (de Villamayor) sus bienes en Bustillo e Iglesias. Junto a Ordoño Pérez III, fue testigo ese mismo año (y el mismo día), cuando los coherederos de Ruy Pérez renunciaron a su herencia en favor también de García Fernández. Seguramente era descendiente de Rodrigo Pérez de Cayuela que se documenta a finales del siglo XI. También

\footnotetext{
${ }^{43}$ En 1216 Gonzalo García de Grajera fue testigo en la venta de Ordoño Pérez de Cabia a Teresa Vermúdez de heredades y rentas en la zona de Aguilar; RoDRíGUEZ, Aguilar, doc. 271. En 1222 Diego García de Grajera figura como testigo en la lista de militibus en el documento que recoge una venta de heredades realizada por Vela García y su mujer a García Fernández y la suya; son heredades en Villaldemiro y Arenas que los vendedores habían recibido de sus abuelos Ordoño Pérez I y doña Urraca; MARTínEZ y GONZÁLEZ, Villamayor, doc. 20. En 1228 Gonzalo García de Grajera y Fernando Ruiz de Grajera fueron testigos cuando Gonzalo Pérez de Padilla y su mujer empeñaron a García Fernández de Villamayor la heredad que tenían en Valdegrajera; Ibid., doc. 32 .

${ }^{44}$ SERRANO, Valcárcel, doc. X. Uno de los fiadores fue Gonzalo Gutiérrrez de Grajera. Tal y como advierte el editor del documento, en la data del documento se señala que el obispo de Burgos era Aparicio, que no lo fue hasta 1247; de manera que debe haber un error en la data que figura en el documento: Facta carta in mense Junius sub era $M^{a} C C^{a} L X X X I I^{a}$ annos; quizás el escriba olvidó una " $V$ " para referirse a la era 1287, año 1249.

${ }^{45}$ LizoAIN, Huelgas, doc. 395. Entre los testigos hidalgos figura Diego Muñoz de Grajera, hijo de Muño' García.
} 
se documenta una María Martínez de Cabia, seguramente noble y que tenía heredades destacables en Cabia, heredades que vendió a don Moriel y que éste vendió al monasterio de Las Huelgas en $1219^{46}$. Uno de los testigos de la lista de infançonibus mencionados en el documento que recoge esa venta fue Vela García, otro de los nietos de Ordoño Pérez I mencionado en el documento de 1194. A él y su familia me referiré a continuación.

\section{LA FAMILIA DE Vela GaRCÍA}

El documento de 1194 nos dice que Vela García, como los demás citados entonces, era nieto de Ordoño Pérez I, pero no conocemos exactamente sus vínculos de parentesco con él. Sabemos que era hijo de García Ordóñez, pero no nos queda constancia documental de la relación entre Ordoño Pérez y García Ordóñez; es probable que fueran padre e hijo, pero tengo algunas dudas. Hubo varios personajes llamados García Ordóñez y no es fácil saber quién de ellos era el padre de Vela García. Sabemos que Vela tenía una hermana llamada Urraca García; un documento que indica la filiación de Urraca con García Ordóñez señala también que las hermanas de éste eran Urraca y Sancha Ordóñez. García Ordóñez casó con Urraca Vermúdez, su hijo Vela García con Teresa y su hija Urraca García con Pedro Núñez de Guzmán $^{47}$.

(Véase Apéndice, cuadro 3).

Los datos sobre su familia permiten identificar al padre de Vela García en algunos documentos y llevan a pensar que la mayor parte de su patrimonio se encontraba en la ribera del Duero (mapa 2$)^{48}$; lo conocemos por las relaciones que sostuvo con los principales monasterios de la zona, el de La Vid y el de Gumiel. García Ordóñez y sus hermanas Urraca Ordóñez y Sancha Ordóñez tuvieron heredades en Villanueva de Gumiel y en Moriel Díaz que dieron a Johannes y a sus hijos en $1196^{49}$. Posteriormente el rey compró esas heredades y las cedió al monasterio de La Vid en 1228 con el consentimiento de Urraca García, que conservaba ciertos derechos sobre

\footnotetext{
${ }^{46}$ Los documentos de referencia en RoDRÍGUEZ-PICAVEA, Calatrava doc. 20; y Registro de escrituras de la Orden de Calatrava, T. I bis, sign. 1341 bis, fol. 18; MARTínEZ y GONZÁLEZ, Villamayor, docs. 47 y 48; GARRIDO, Catedral, doc. 224; LIZOAIN, Huelgas, doc. 136.

${ }^{47}$ Los datos sobre el parentesco en MARTíNEZ y GọZÁLEZ, Villamayor, doc. 13; GONZÁLEZ, Fernando III, T. 2, doc. 240; y AHN, Clero, Pergaminos, carp. 380, n⿳⺈ 1 y 3 . Enseguida volvere sobre estos documentos.

${ }^{48}$ No desçarto que el parentesco de Vela García con Ordoño Pérez I fuera por línea materna, lo que podría explicar que no aparezca García Ordóñez en el documento de 1194 y que su patrimonio se centre en otra zona diferente. Sin embargo, recuérdese que se documenta una serna cerca de San Pedro de Berlangas que fue de Ordoño Pérez y que en algún momento figura también en manos de García Ordóñez. GARRIDO, Catedral de Burgos, doc. 315 de 1194; y vease lo dicho más arriba en la nota 10.

${ }^{49}$ Índice... La Vid, doc. 139; y el texto completo en AHN, Clero, Pergaminos, carp. 379, $\mathrm{n}^{\circ}$ 9. Nótese que, según se indica en el documento, se trata de bienes que habían recibido en herencia: illam hereditatem quam heremus.
} 
ellas $^{50}$. García Ordóñez tuvo también heredades en Hontoria de Valdearados, donde disfrutó además en prestamo de la casa que poseía el monasterio de La Vid, y fue probablemente el señor de la villa de Quemada. En 1222, el monasterio de La Vid les entregó a él y a su mujer, Urraca Vermúdez, en emprestamo la casa que el monasterio tenía en Hontoria con las heredades a ella adscritas, casas, heredat, uinas...; a cambio ellos debían entregar al monasterio el diezmo de lo que produjeran esos bienes y el monasterio les obligaba a que fagades fazer la presa al conceio de Fontoria e fagades uos fazer el molino hi las casas. E que saquedes la heredad toda ques malmetida de quanto nos uos mostraremos cartas. A la muerte de García Ordóñez y su mujer la casa volvería a manos del monasterio con las mejoras realizadas: con bueis e con ganado e con pan e con uino e con ropa e con quanto en la casa ouiere e quanto que hi meioraredes en casas hi en aquesta heredat que uos damos, que todo finque e preste por uuestras almas a Sancta Maria de la Vid. Pero García también se comprometía a entregar al monasterio todas sus viñas en Hontoria, le concedía comunidad de pastos con la villa de Quemada y derechos para el huerto y el molino del monasterio en el río de Quemada y también le entregaba sus collazos de Torregalindo (Aza) para saldar una deuda de 780 maravedís con el monasterio ${ }^{51}$. El hecho de que den al monasterio pastos comunes con la villa de Quemada (E otorgamos uos que pascan uuestros gandos con los de Quemada por o que ellos pascieren, $i$ el rio de Quemada que non uos le pueda nenguno contrariar por al molino e por al orto de Ribiella) nos lleva a pensar que García Ordóñez y Urraca Vermúdez fueron señores de Quemada. Ambos lugares, Hontoria de Valdearados y Quemada están próximos, al noreste de Aranda de Duero. Como veremos más adelante, Quemada pasó después a manos de Urraca García, la hija de García Ordóñez y de su esposo Pedro Núñez de Guzman. La cesión en prestimonio de la casa de Hontoria, nos informa también de que García Ordóñez tuvo campesinos dependientes, collazos, en Torregalindo que se comprometió a entregar al monasterio de La Vid en 1222. Para 1226 ya había muerto y esos collazos no estaban en manos del monasterio sino de su hija Urraca García y su marido Pedro Núñez de Guzmán. Estos últimos dieron en 1226 al monasterio la heredad y los collazos que tuvo García Ordóñez en Torregalindo y en Fuentenebro, ambos lugares próximos en la zona de Aza, exceptuando, como ya vimos más arriba, los bienes que García Ordóñez había comprado a Ordoño Pérez ${ }^{52}$. Urraca Vermúdez, la esposa de García Ordóñez tuvo heredades en Villanuño, Villateresa y Mañalecos, también en la zona del

\footnotetext{
${ }^{50}$ GonZÁLEZ, Fernando III, T. 2, doc. 240.

${ }^{51}$ Índice... La Vid, doc. 144; y el texto completo (de donde tomamos las citas) en AHN, Clero, Pergaminos, carp. $380, \mathrm{n}^{\circ} 1$.

${ }^{52}$ Índice... La Vid, doc. 146; y el texto completo en AHN, Clero, Pergaminos, carp. 380, $\mathrm{n}^{0} 3$. Véase más arriba la nota 32 y el texto a que se refiere.
} 
Esgueva; heredades que después, en 1246, estaban en manos de su hija Urraca García quien las vendió, junto a su marido, al monasterio de Gumiel ${ }^{53}$.

El hijo varón de García Ordóñez, Vela García, también tuvo intereses en la zona de la ribera del Duero, aunque conocemos mejor su patrimonio en la zona de Muñó (mapa 2). En 1205 vendió heredades en San Román al monasterio de Arlanza ${ }^{54}$. Vendió también algunas heredades en la zona de Muñó a García Fernández de Villamayor: en 1216 las heredades de Vilviestre de Muñó que tenía con su hermana Urrca y en 1222 las de Villaldemiro y Arenas $^{55}$. De estas últimas se dice que las había heredado de Ordoño Pérez y de doña Urraca, que eran sin duda sus abuelos citados en el documento de 1194. Sus propiedades en la ribera del Duero están peor documentadas pero sabemos que tuvo collazos y heredades en Villalobón, en la zona de Roa, y también en Gumiel y en Espinosa de Cervera. En los tres casos nuestra información sobre ellas es indirecta. En Villalobón Vela García compró heredades (el ochavo, la octava parte de la villa) al padre de Alfonso García de Valera y después las vendió al monasterio de San Pedro de Gumiel. Lo sabemos porque después Alfonso García de Valera y sus hermanos pleitearon por esas heredades con el monasterio de Gumiel, con el que alcanzaron un acuerdo en $1254^{56}$. Las heredades de Gumiel también las vendió al monasterio de Gumiel y éste en 1231 las cedió, junto a otras, a Ordoño Pérez ${ }^{57}$. En cuanto a las heredades de Espinosa de Cervera, se las menciona entre los límites de otras que vendió su pariente Ordoño García de Castil Sarracín al monasterio de Silos en 1222; además, en el documento de la venta confirma entre los labradores Garsia de la Horra, qui est iudex de don Bela ${ }^{58}$. Por último, también tuvo heredades en Toledo y en Algurilla que vendió a la orden de San Juan por 350 maravedís en 1209; vendió estas heredades junto

\footnotetext{
${ }^{53}$ AHN, Clero, Pergaminos, carp. 231, $\mathrm{n}^{0} 16$ de 1246. Hay otra referencia que también podría corresponder a propiedades de García Ordóñez. Se trata de la donación realizada por un individuo de ese nombre a la orden de Santiago en 1197 de todas las heredades que tiene en Carrantona, lugar cuya ubicación desconozco. Dado que el nombre no es infrecuente sería arriesgado plantear la identificación con nuestro García Ordóñez, más aún tratándose de un lugar sin localizar, pero uno de los testigos se identifica como de Chemada (Quemada) y eso sí creo que es un elemento a tener en cuenta. AHN, OO.MM. Orden de Santiago, carp. $102, \mathrm{n}^{\circ} 5$. Entre la documentación de la orden de Santiago no he encontrado otras referencias a García Ordóñez ni al lugar de Carrantona; véase M.A. PÉREZ CASTAÑEDA, Indice onomástico y toponimico del "Inventario del Archivo del Convento de Uclés” por Juan Antonio Fernández, Madrid, 1985, mecanografiado, Sala de Investigadores del AHN, sign. 8 de la Sección de Ordenes Militares.

${ }^{54}$ Recoge la noticia L. SERRANO en Cartulario de Arlanza, p. 253, nota 2, donde le cita como hijo de García Ordóñez de Villamayor. Señala que fueron testigos Ordoño Pérez de Cabia, Gonzalo Armíllez, Armillo de Hormaza, Gonzalo Gutiérrez de San Román y Pelayo, merino.

${ }^{55}$ MARTÍNEZ y GONZÁLEZ, Villamayor, docs. 13 y 20.

${ }^{56} \mathrm{AHN}$, Clero, Pergaminos, carp. 232, no 5. Merece la pena destacar que en este texto se le denomina Vela García de Villamayor, denominación con la que se vendría a destacar el parentesco con García Fernández de Villamayor.

${ }^{57}$ GonZÁLEZ, Fernando III, T. 2, doc. 369; y AHN, Clero, Pergaminos, carp. 231, no 7.

${ }^{58}$ Vivancos, Silos, doc. 104.
} 
a su hermana Urraca García, de manera que parece claro que se trata de bienes heredados de sus padres ${ }^{59}$.

Vela García tuvo alguna proyección, aunque muy escasa, en el entorno regio. El rey le incluye en una ocasión en 1220 entre toda una serie de baronibus et nobilibus meis, entre los que aparecen otros parientes y en cuya presencia confirmó una sentencia sobre unas propiedades del monasterio de La Vid ${ }^{60}$. Conocemos el nombre de la mujer de Vela, Teresa, puesto que figura junto a él en algún documento ${ }^{61}$, pero no tenemos otros datos sobre la familia de Teresa, ni sobre los hijos de ambos, si es que los tuvieron. Pero sî están bien documentados su hermana Urraca García y el marido de ésta Pedro Núñez de Guzmán.

Mediante su matrimonio, Urraca enlazó con una familia más poderosa, los Guzmán, que forman un grupo familiar amplio, dividido ya en dos grandes ramas integradas por los descendientes de Nuño Pérez y de Guillén Pérez de Guzmán, ambos hermanos e hijos de Pedro Ruiz de Guzmán, mayordomo de Alfonso VIII. Pedro Núñez de Guzmán, el esposo de Urraca García, es hijo de Nuño Pérez y podríamos decir que se desenvolvía entre los círculos de la nobleza media y de la alta nobleza. En el repartimiento de Sevilla recibió un donadío menor, no un donadío mayor como los ricos-hombres, y tampoco figura como confirmante en los privilegios de Fernando III $^{62}$. En Castilla su patrimonio se concentraba en las zonas entre el Esgueva y el Duero y algo más al sur en las zonas de Aza y Montejo, no lejos del propio lugar de Guzmán, cerca de Roa, del que tomaron su apellido (mapa 2).

Hemos visto como Urraca García tenía algunos bienes conjuntamente con su hermano Vela, bienes que procederían de la herencia de sus padres. En concreto, en Toledo y en Algurilla, que vendieron a la orden de San Juan en 1209, y en Vilviestre de Muñó, que vendieron en 1216 a su pariente García Fernández (de Villamayor) ${ }^{63}$. Por herencia de su padre García Ordóñez, Urraca García y su marido Pedro Núñez de Guzmán también tuvieron

\footnotetext{
${ }^{59}$ AyAla, San Juan, doc. 203. Recuérdese que Inés y María, hijas de su pariente Ordoño Pérez también tenían heredades en Toledo y Algurilla, que en 1202 dieron a la orden de Calatrava; RoDRÍGUEZ-PICAVEA, Calatrava, doc. 126. Véase más arriba la nota 27 y el texto a que se refiere. Parece tratarse de heredades que proceden de un tronco común.

${ }^{60}$ Pleiteaban el monasterio de La Vid y Lope Díaz (de Haro) sobre Alcolea en Guadalajara. La sentencia, favorable al monasterio puesto que Lope Díaz desistió, fue dictada por el mayordomo del rey Gonzalo Rodríguez (Girón) y el mayordomo de la reina García Fernándẹz (de Villamayor). En el grupo de los que estaban presentes cuando el rey confirmó la sentencia figuran, junto a Vela García, varios parientes de García Fernández, como sụs tíos Rodrigo y Abril García. Se menciona también a Ordọño García, quien pudiera ser otro pariente de Vela, Ordoño García de Castil Sarracín, que también se menciona en el grupo de 1194. GonZÁLEZ, Fernando III, t. 2, doc. 119.

${ }^{61}$ MARTÍneZ y GONZÁLEZ, Villamayor, doc. 20.

${ }^{62}$ Es un grupo familiar bastante complejo, la mejor visión general sobre él es la ofrecida por Moxó en De la nobleza vieja a la nobleza nueva, pp. 112-123; también aportan datos de interés GONZÁLEZ en Alfonso VIII, T. 1 , pp. 268-269 y Fernando III, T. 1, pp. 150-151; y M. GAIBROIS en Historia del reinado de Sancho IV de Castilla, Madrid, 1922-1928, t. 2, pp. 335-338. Los datos del repartimiento en GONZÁLEZ, Repartimiento de Sevilla, t. 2, pp. 43, 44 y 241.

${ }^{63}$ AyAlA, San Juan, doc. 203; y MARTíneZ y GonZÁleZ, Villamayor, doc. 13.
} 
heredades en Torregalindo y en Fuentenebro, en la zona de Aza, como también hemos mencionado ya. Pero, además de esos, es posible que Pedro Núñez también tuviera otros bienes en Torregalindo procedentes de su propia herencia o adquiridos por él en algún otro momento ${ }^{64}$.

Conocemos otros bienes de Pedro Núñez y Urraca García en la zona por la relación que tuvieron con el monasterio de San Pedro de Gumiel de Izán, que en esos momentos estaba inmerso en el proceso de formación de su dominio $^{65}$. Relaciones contradictorias, puesto que este monasterio integró en su dominio bienes vendidos por Pedro Núñez y otros miembros de su familia, pero la formación de un nuevo dominio en la zona suponía un factor de desestabilización por la competencia con los otros poderes señoriales establecidos.

En 1246, Pedro Núñez y Urraca García vendieron por 130 maravedís al monasterio de San Pedro de Gumiel las heredades que tenían en Villanuño, Villateresa y Mañalecos. Son heredades que, como se señala en el texto, procedían de la herencia de Urraca García y habían pertenecido a su madre Urraca Vermúdez ${ }^{66}$. Sólo dos años más tarde tenemos noticias de un pleito con el monasterio protagonizado por ellos mismos, pleito que debió llegar a concretarse en acciones violentas que desembocaron en algunas muertes. Pedro Núñez y Urraca habían vendido al monasterio también la villa de Quemada y a cambio el monasterio les había entregado las heredades que tenía en las villas de Montejo, Milagros, Santa Cruz, Pardilla, Tamarón, Aranda, etc. El incumplimiento de alguna de las cláusulas de la venta, que no conocemos, ocasionó que Pedro Núñez demandara al monasterio heredades en Vadocondes y que se posesionara de las de Baños de Valdearados, dando lugar a un pleito que, como decimos, debió desembocar en algunos episodios violentos. El pleito fue emplazado ante el rey por el merino mayor, Fernando González de Rojas, y el rey decidió que lo librara su hijo el infante Alfonso, que nombró, a su vez, a los jueces árbitros: los maestres de Alcántara y Calatrava, el prior de San Juan y Pedro Ruiz de Olmos. La sentencia dictada por el infante Alfonso obligaba a deshacer la venta anterior, renunciando Pedro Núñez a las heredades de Vadocondes y conservando las de Baños por en sus dias. Además obligaba al monasterio a revender la villa de Quemada a Pedro Núñez y a su mujer por 3.500 maravedís, aunque el monasterio pudiera conservar en ella algunos derechos que se concretaban en el derecho de recoger tres cargas de leña diarias y en pastos para 300 ovejas. Se especifica también la forma de pago de esos 3.500 maravedís: 2.000 deberían ser entregados inmediatamente al monasterio por Pedro Núñez y Urraca García, y mientras no pagaran el resto, la villa la tendría en tenencia un monje del monasterio; ellos conservarían sus derechos sobre la villa, pero las rentas

\footnotetext{
${ }^{64} \mathrm{AHN}$, Clero, Pergaminos, carp. 380, $\mathrm{n}^{\circ}$ 3. Las indicaciones que acompañan a los campesinos de Torregalindo que fueron testigos cuando el monasterio accedió de forma efectiva a esos bienes, llevan a pensar que Pedro Núnez poseía otros bienes en la villa.

${ }^{65}$ Sobre él véase Álvarez PAlENZUELA, Monasterios cistercienses, pp. 97-100 y 222-227.

${ }^{66} \mathrm{AHN}$, Clero, Pergaminos, carp. 231, no 16.
} 
las recogería el monje y las entregaría al monasterio en almosna por el alma de don Pero Nunnez et de domna Urraca Garcia, hasta que no se pagara el precio total. Por otro lado, en la sentencia también se ordena a Pedro Núñez y su mujer que confirmen la avenencia hecha en un pleito anterior con el monasterio por razón de las heredades de Villanuño, Villateresa y Mañalecos, obligando al monasterio a entregarles cien cargas de pan anuales durante su vida $^{67}$.

Conflictos, por lo tanto, largos y complejos. La sentencia se refiere, como vemos, también a la villa de Vadocondes, diciendo que Pedro Núñez reclamó heredades allí del monasterio de Gumiel, aunque se le obliga a renunciar a ellas. Esto se declara en 1246, pero ya consta en un documento de 1240 que Pedro Núñez y Urraca García vendieron por 100 maravedís al monasterio de Gumiel la villa de Vadocondes que tenemos forçada ${ }^{68}$. Otro documento de 1253 recoge otro cambio con el monasterio de Gumiel; ahora Pedro Núñez y Urraca García entregan al monasterio todas sus heredades en Milagros y reciben a cambio las que el monasterio tenía en Santa Cruz y en Tamarón $^{69}$. Pero no sólo tuvieron conflictos con el monasterio de Gumiel, sino también con otros próximos como el de La Vid. Hemos visto como le vendieron en 1226 heredades en Torregalindo y Fuentenebro; pues bien, años más tarde, habían entrado las heredades que el monasterio tenía en otro lugar próximo, en Fuentelcesped. En 1254 revendieron al monasterio las heredades de las que se habían apropiado por 1.000 maravedís $^{70}$.

Pedro Núñez de Guzmán y su mujer Urraca García tuvieron también propiedades en Caleruega, igual que otros miembros de la familia Guzmán, donde su antepasado Domingo había levantado un hospital ${ }^{71}$ y donde después el rey fundaría en 1266 un monasterio de monjas de la Orden de Predicadores. El rey querrá entregar la villa al monasterio y para ello tendrá que adquirir todas las heredades y divisas que en ella tenían sus diviseros, puesto que se trataba de un lugar de behetría. A tal fín, en ese año, Urraca García, ya viuda, entregó al rey sus bienes y derechos en la villa, mientras que su hijo, Juan Pérez de Guzmán, hará lo propio directamente con el monasterio. Aunque en 1248 Urraca ya había vendido al obispo de Osma otras heredades en Caleruega para la iglesia y hospital de Santo Domingo de esa villa ${ }^{72}$. En otras

\footnotetext{
${ }^{67} \mathrm{El}$ documento donde se recoge la sentencia correspondiente fue publicado por C. SÁNCHEZALBORNOZ en Algunos documentos procesales del reino de León y Castilla de 1050-1300, en Viejos y nuevos estudios sobre las instituciones medievales españolas, t. 3, Madrid, 1980, pp. 1.765-1783, doc. XII en pp. 1.779-1981.

${ }^{68}$ AyALA, San Juan, doc. 275.

${ }^{69} \mathrm{~A}$. Guglieri NAVARro, Catálogo de sellos de la sección de sigilografía del Archivo Histórico Nacional, t. III, Sellos de Ordenes Militares, Corporaciones, Particulares, Varios, Madrid, 1974, 2121 , p. 156.

${ }^{70}$ Índice... La Vid, doc. 147 (aunque la transcripción que ofrece tiene algunas deficiencias); y AHN, Clero, Pergaminos, Carp. 380, $\mathrm{n}^{\mathrm{o}} 11$.

${ }^{71}$ GoNZÁLEZ, Fernando III, t. 3, doc. 613.

${ }^{72}$ Los documentos en E. MARTínez LIÉBANA, Colección diplomática del Real Convento de Santo Domingo de Caleruega, Vergara, 1931 (= MARTINEZ, Caleruega), docs. CCXXXIV, CCXXXII y CCXVII.
} 
zonas del reino, se conocen propiedades de Pedro Núñez de Guzmán en Toledo y también consta, como ya he indicado, que recibió un donadío menor en el Repartimiento de Sevilla ${ }^{73}$.

Del hijo de Pedro Núñez y Urraca García, Juan Pérez de Guzmán, conocemos que tuvo heredades también en Boadilla del Camino y en Vega de Doña Olimpa, en la actual Palencia, y más al sur en las zonas del Esgueva y el Duero tuvo heredades también en Villajimeno; heredó de su padre la villa de Quemada y fue señor también de Cilleruelo de Abajo y de Gumiel del Mercado $^{74}$.

\section{LOS CASTIL SARRACÍN}

Otros dos de los personajes que donaron al obispo su parte en la heredad de Las Hormazas en 1194 fueron Ordoño García y García García. Ambos eran hermanos y solían acompañar su nombre con el topónimo de Castil Sarracín en referencia al castillo o la fortificación de Sarracín, un lugar cercano a Burgos, a unos 7 u $8 \mathrm{kms}$ al sur de la ciudad, y muy próximo también a Cabia, que tomaron como referente algunos de sus parientes, según hemos visto. Eran hermanos de Inés y creo que también de Mencía y de Sancha García, e hijos de García García. Como en los otros casos, no conocemos su parentesco exacto con Ordoño Pérez I y Urraca Fernández. (Véase Apéndice, cuadro 4). Conocemos propiedades de Ordoño García y su hermano en villas próximas a la ciudad de Burgos, en la comarca de Muñó y un poco más al sur en zonas cercanas al Duero (mapa 3). En las proximidades de Burgos, unos kms al norte, estaba Sotragero, donde ambos hermanos tenían abundantes propiedades heredadas de su padre. En 1200 Ordoño García vendió las suyas y las de su hermana Inés a don Esteban de la Cruz por 867 maravedís y dos años más tarde hizo lo mismo su hermano García García por 433 maravedís. Ambos documentos muestran claramente que la herencia paterna fue dividida en partes iguales, aunque Ordoño disponían en 1200 de la suya y de la de su hermana Inés. En total, el conjunto de los bienes que vendieron a Esteban de la Cruz consistía en dos casas, 24 tierras, un pajar y

\footnotetext{
${ }^{73}$ En Toledo tenía unas casas que limitaban con una mezquita que pertenecía a la catedral de Toledo y que ésta dio en prestamo en 1254. Veáse la noticia del documento en GONZÁLEZ, Repartimiento de Sevilla, T. 2, p. 323 . En Sevilla el rey dio a varios miembros del grupo familiar de los Guzmán Gazullurva, en Aznalfarache, al que cambió el nombre por Guzmán. En concreto a Pedro Núñez le entregó 150 aranzadas y otras 15 yugadas de pan en Alhazaín en Facialcázar; junto a otros parientes le entregó también el barrio de Benimahut; véase Ibid.. pp. 43, 44 y 241 . Conviene no confundir a Pedro Núñez de Guzmán con otro pariente llamado Pedro Gưzmán que también recibió heredades en el Repartimiento de Sevilla pero que alguna ocasión figura integrando un grupo de ricos hombres a los que el rey dio heredades en Aznălcázar; Ibid., p. 267 y otras propiedades suyas en pp. 43, 44, 155 y 241 .

${ }^{74} \mathrm{~L}$. SALAZAR Y CASTRO Historia genealógica de la casa de Lara Madrid 1696, T, 4 , Pruebas, p. 673, doc. de 1275; MARTÍNEZ, Caleruega, docs. CCXLVIII, CCXLIX y XXII de 1274 y 1277; LIZOAIN, Huelgas, doc. 593 de 1279; y F. J. PEREDA LLARENA, Documentación de la Catedral de Burgos (1254-1293), Burgos, 1984, doc. 192 de 1285.
} 
una era ${ }^{75}$. También cerca de Burgos, en este caso unos kms al oeste, se encuentra Castrillo del Val, donde tuvieron igualmente heredades Ordoño García y su hermana Mencía, en concreto 4 solares, que vendieron al monasterio de Ibeas en 1201 por 41 maravedís $^{76}$. En zonas próximas, aunque no consta documentalmente, podemos pensar que Ordoño García y García García tuvieron también bienes en Sarracín. La identificación de Mencía como hermana de Ordoño García y de García García, además de Inés, me lleva a pensar que también eran hermanos de Sancha García. Un documento de 1196 recoge como los hermanos Ordoño García, García García y Mencía vendieron a su otra hermana Sancha García por 100 áureos y una capa en robra las heredades que tenían en Frandovínez, también muy cerca de Burgos, al suroeste, y en Villa Bela (creo que Villovela de Esgueva, en la zona del Duero) ${ }^{77}$.

En la zona de Muñó, en Vilviestre también se conocen heredades de Ordoño García y de su sobrino Rodrigo Rodríguez, que vendieron a García Fernández (de Villamayor) en 1216. Es frecuente que los diversos miembros del grupo familiar posean heredades en las mismas villas, como sucede en Vilviestre $^{78}$. Otra de esas villas era Espinosa de Cervera, situada más al sur en el Esgueva. Aquí también eran abundantes los bienes de Ordoño García. En 1222 vendió al monasterio de Silos la heredad que tenía aquí y en el villare de Quintanilla - próximo a Espinosa - y además nueve solares poblados y otro despoblado en Espinosa, reservándose para sí las divisas y otro solar; al hacerse relación de las heredades vendidas sabemos que consistían en 19 tierras, tres linares, dos huertos y dos viñas en Espinosa y otras once tierras en Quintanilla. El documento correspondiente muestra que en esta villa poseían heredades bastantes miembros del grupo familiar: Ordoño Pérez de Cabia y Vela García, como hemos indicado más arriba, pero también Rodrigo Rodríguez y la abadesa de Renuncio; además, las heredades de unos y otros

${ }^{75}$ LIZOAIN, Huelgas, docs. 56 y 58. Se conserva otro documento en el que los dos hermanos hacen relación detalladá de los bienes que venden a Esteban de la Cruz; Ibid., doc. 59. Muchas de las tierras vendidas limitan con otras de doña Mencía que, como se verá a continuación, creo que también era hermana de Ordoño García y García García.

${ }^{76}$ MARTínEZ, Ibeas, doc. 32. He tenido algunas dudas al identificar a estos personajes con los Castil Sarracín, pero creo que sí se trata de ellos porque el documento fue realizado en Castrillo del Val y en Castil Sarracín ("hec carta fuit rata et roborata in concilio det (sic) Castrillo et in concilio de Castil Seracin"); el primer testigo es García García, que se identifica como "suo ermano de Ordoño G.", refiriendose sin duda al vendedor; y porque entre los testigos figuran también varios de Sarracín y el propio concejo ("et concilio de Vila Serraçin testis").

${ }^{77}$ L. Serrano, Los Armíldez de Toledo y el monasterio de Tórtoles, "Boletín de la Real Academia de la Historia", CIII (1933), pp. 69-140 (= SERRANO, Tórtoles), doc. IV. Sin embargo, la identidad de Sancha García todavía me ofrece algunas dudas, como señalaré más adelante.

${ }^{78}$ MARTÍNEZ y GONZÁLEZ, Villamayor, doc. 12. Recordemos que el mismo ạno vendieron también Vela García y Urraca García a García Fernández sus heredades en Vilviestre y por la misma cantidad. Parece claro que las heredades de Ordoño García de Castil Sarracín y las de Vela García forman parte de una herencia común. Ambos, por cierto, Ordoño y Vela, fueron fiadores uno del otro en sus respectivas ventas a su pariente más poderoso. 
limitaban entre sí muy frecuentemente, de manera que se puede pensar en una procedencia de todas ellas de algún antepasado común ${ }^{79}$.

Rodrigo Rodríguez actúa concediendo esta venta y como fiador; era sobrino de Ordoño García, como ya he mencionado, aunque no conozco la relación exacta de parentesco. Su padre fue Rodrigo Díaz ${ }^{80}$. Creo probable que Rodrigo Díaz estuviera emparentado con Sancha y García Díaz, quienes constan como propietarios en Villaldemiro ${ }^{81}$.

Según hemos visto, Rodrigo Rodríguez de Castil Sarracín tuvo heredades en Vilviestre de Muñó y en Espinosa de Cervera ${ }^{82}$ (mapa 3). Tuvo también propiedades en Santa María de Añuéquez, no lejos de Lerma, que vendió a García Fernández (de Villamayor) en 1222 y, a juzgar por el precio -700 maravedís-, debían constituir un conjunto importante de bienes ${ }^{83}$. También tuvo heredades en Padilla de Abajo, al oeste de Burgos, cerca de Melgar, que vendió al monasterio de San Miguel de Villamayor de Treviño en 1223 por 30 maravedís y un manto en robra ${ }^{84}$. Y también consta como

\footnotetext{
${ }^{79}$ ViVANCOS, Silos, doc. 104. Entre tierras, linares, huertos, viñas y solares en Espinosa y en Quintanilla se citan 39 unidades y, aunque no de todas se dan los límites con precisión, 16 limitan con otras propiedades de Vela García, 10 con otras de Ordoño Pérez de Cabia, 7 de Rodrigo Rodríguez y otras 7 de la abadesa de Renuncio. Véanse también las notas 28 y 57 y el texto correspondiente.

Conviene señalar también que, tal y como he indicado más arriba, creo que Ordoño García de Castil Sarracín puede corresponder con el individuo llamado Ordoño García que figura en 1220 entre los barones y nobles del rey cuando Fernando III confirmó una sentencia favorable a intereses patrimoniales del monasterio de La Vid. Entre esos barones y nobles estaba también su pariente Vela García y otros parientes de García Fernández (de Villamayor) que fue uno de los que dieron la sentencia que confirmó el rey. Véase GonZÁLEZ, Fernando IIII, T.2, doc. 119; y más arriba la nota 59 y el texto a que corresponde.
}

${ }^{80}$ MARTínez y GonzÁLEZ, Villamayor, doc. 19. Cabe pensar que Rodrigo Díaz fuera el marido de alguna de las hermanas de Ordoño García: Inés, Mencía o Sancha; o bien que perteneciera a la familia de la esposa de Ordoño, cuyo nombre no se conoce.

Un documento fechado en 1204 recoge una venta hecha por Lope Díaz, hijo de Diego López merinus qui fuit regi, a Esteban de la Cruz y su esposa de la heredad que tiene en Castil Sarracín y en Villaolda con solares poblados, etc., por $400 \mathrm{mrs}$. El primer testigo citado en ese documento es Rodrigo Díaz, hijo de Diego López; por lo tanto, hermano del vendedor, ambos hijos del merino regio Diego López. M.C. PALACÍN, GÁLVEZ, y L. MARTÍNEZ GARCÍA, Documentación del hospital del Rey de Burgos (1136-1277), Burgos, 1990 (= PALACÍn y MARTínEZ, Hospital del Rey), doc. 25. Creo que podemos identificar a este Rodrigo Díaz con el padre de Rodrigo Rodríguez. En cuanto al merino regio Diego López ha de corresponder con el merino mayor de Castilla Diego López de Fitero hijo, a su vez, del merino mayor anterior, Lope Diaz de Fitero. Sobre ellos véase GoNZÁLEZ, Alfonso VIII, T. 1, pp. 245-248; y, a falta de un estudio más detallado, algunos datos en I. ALVAREZ BORGE, Monarquía feudal y organización territorial. Alfoces y merindades en Castilla (siglos X-XIV), Madrid, 1993, pp. 169-170.

${ }^{81}$ En 1179 Sancha dio todas sus heredades y las de su hermano García Diaz en Villaldemiro a su sobrino Diego García; MARTíNEZ y GONZĂLEZ, Villamayor, doc. 3; también R. MENÉNDEZ PIDAL, Documentos lingüisticos de España, t. I, Madrid, 1966, doc. 150. Es interesante señalar que uno de los testigos de este documento es García García de Castil Sarracín. Según señala SERRANO, años más tarde García Fernández de Villamayor y su esposa Teresa adquirieron esas heredades a Diego García; véase El mayordomo mayor, p, 111 nota 3; sin embargo no he visto el doccumento correspondiente que no fue editado en su dia por Serrano, ni figura tampoco en la edición más reciente de los documentos del monasterio de Villamayor.

${ }^{82}$ Las de Vilviestre las vendió con su tío Ordoño García a García Fernández (de Villamayor) en 1216. Las de Espinosa se mencionan en el documento la venta de las de su tío al monasterio de Silos. MARTíneZ y GONZÁLEZ, Villamayor, doc. 12; y VivanCOS, Silos, doc. 104.

${ }^{83}$ MARTíneZ y GonzÁLEZ, Villamayor, doc. 19. Este es el único documento que indica la filiación de Rodrigo Rodríguez con Rodrigo Díaz.

${ }^{84} \mathrm{AHN}$, Clero, Códices, 998B, fols. 12v-13r; utilizo la transcripción de P. AzCÁRATE quien ha tenido la amabilidad de facilitarme el manuscrito de su transcripción del Cartulario de Treviño; véase el doc. 35 . 
propietario, igual que otros de sus parientes, al sureste de Burgos, en la zona de Juarros. En 1224 Rodrigo Rodríguez vendió al monasterio cisterciense de Bujedo de Juarros sus heredades y collazos en Revilla del Campo y Revilla de la Fuente, ambas villas próximas al monasterio, pero sus heredades en la zona de Juarros eran más abundantes, como se muestra en una nueva venta hecha al mismo monasterio tres años más tarde, en 1227, en la que se incluyen propiedades vendidas ya en 1224 y otras más en dos villas cercanas: Salguero de Salce y Quintana ${ }^{85}$. Rodrigo Rodríguez tuvo también propiedades en la villa con cuyo topónimo acompañaba a su apellido, Sarracín; en 1227 vendió al hospital del Rey por 50 maravedís los bienes que había recibido en esta villa de doña Sancha García ${ }^{86}$.

El hijo de Rodrigo Rodríguez fue Alfonso Ruiz, que está relativamente bien documentado y mantuvo vínculos estrechos con el hospital del Rey de Burgos, vínculos que han llevado a L. Martínez, el principal estudioso del hospital, a señalar que "no habían de quedar reducidas las relaciones al marco de los negocios" $"$.

Se conocen propiedades suyas en villas de la zona de Villadiego y en Sarracín, donde debían ser muy abundantes (mapa 3). En 1232 entregó al hospital del Rey de Burgos las propiedades que tenía en Villolda, junto a Sarracín, y recibió a cambio los bienes del hospital en Villahernando de Treviño, algunas tierras en Villalbilla de Villadiego, Boada y La Mora (ambas también cerca de Villadiego) y las sernas que le debían hacer los hombres de Villahernando, Boada y La Mora, más 100 mrs. y una mula ${ }^{88}$. En Sarracín, Alfonso Ruiz tenía bienes importantes: derechos en un molino, heredades y solares poblados por campesinos dependientes, divisa, parte del castillo del lugar - de ahí el topónimo del apellido de su familia-, una dehesa y la iglesia de Santa María. De todo ello se desprendió vendiéndoselo al hospital del Rey y al obispo de Burgos. Las ventas más significativas son en 1242, pero ya en 1238 vendió al hospital del Rey por 42 maravedís diez veces y media en el

${ }^{85}$ Álvarez Palenzuela, Monasterios cistercienses, pp. 208-209 notas 265 y 266; AHN Clero, Pergaminos, carp. 170, n⿳0 ${ }^{\circ} 2$ y n⿳⺈, y MENÉNDEZ PIDAL, Documentos lingúisticos, doc. 179.

${ }^{86}$ PALACÍn y MARTíneZ, Hospital del Rey, doc. 119. Lamentablemente esta referencia se conserva sólo en una breve noticia, lo que nos priva de detalles que pudieran ser esclarecedores. En esa noticia se señala que Sancha García era hija de García Pérez de Fuentearmejil, lo que me hace dudar de que se trate de la hermana de Ordoño García de Castil Sarracín (según hemos visto más arriba en el documento citado en la nota 76) quien, como he señalado, se documenta como hijo de García García. Puede tratarse de personajes diferentes, pero el hecho de que Sancha García tenga propiedades en Castil Sarracịn me llevaría a dudarlo; podría tratarse de hermanastros, hijos de la misma madre pero de distinto padre. Esta Sancha García se documenta en otros textos como hija de García Pérez de Fuentearmejil y de Ana Armíldez y también como sobrina y criata de María Armíldez y Gonzalo Pérez de Torquemada, fundadores del monasterio de Tórtoles de Esgueva; SERRANo, Tórtoles, doc. VI.

${ }^{87} \mathrm{~L}$. MATRÍNEZ GARCÍA, El hospital del Rey de Burgos. Un señorío medieval en la expansión y en la crisis (siglos XIII y XXIV), Burgos, 1986, p. 174.

${ }^{88}$ Realizó el cambio con la abadesa del monasterio de Las Huelgas, de quien dependía el hospital del Rey. PALACÍn y MARTínEZ, Hospital del Rey, doc. 156. Interesa señalar que hizo el cambio con el otorgamiento de su tío Fernan Ruiz, que también fue fiador. A él me referiré más adelante. El cambio era suficientemente importante como para ser confirmado por el rey unos meses más tarde; Ibid., doc. 158, y GonZÁLEZ, Fernando III, t. 2, doc. 477. 
molino que estaba situado cerca de la iglesia de Castil Sarracín ${ }^{89}$. En 1242 vendió al hospital, por la importante cantidad de 2.000 maravedís, todas sus heredades en la villa excepto la divisa, la parte que tenía en el castillo y en la dehesa y la iglesia de Santa María cercana a la villa, con el heredamiento que pertenece a la iglesia ${ }^{90}$. Parte de esos otros bienes y derechos los vendió unos meses más tarde al obispo por 2.500 maravedís; en concreto, la parte que tenía en el castillo y la parte que tenía en la dehesa cerca de Santa Eulalia, mientras que la iglesia la entregó en donación al obispo. La donación y la venta al obispo nos habla también de las intensas relaciones con el hospital del Rey, puesto que encargó a a fray Fernando, clérigo del hospital, que entregara la iglesia y las heredades vendidas al mayordomo del obispo. Las ventas al hospital y al obispo constituyen operaciones importantes, tal y como se refleja en el precio, y quizás tras ellas pudiera haber algunas otras razones que no se expusieron en los documentos. Algo de eso se da a entender cuando se elabora otro documento en el que Alfonso Ruiz declara que, si por alguna razón (que no se especifíca) no pudiera hacer efectiva la venta de sus heredades en Castil Sarracín al obispo, deberá entregarle 600 maravedís del total de 2.500 en que se fijó el precio de la venta ${ }^{91}$. Por último, en 1251 vendió también al hospital del Rey todas las heredades que tenía en La Mora por 100 maravedís y un sombrero en robra ${ }^{92}$.

En alguna de estas ventas figura como otorgante su tío, Fernán Ruiz, que también actúa como fiador en varias de ellas, así como su primo cormano Juan Fernández el Niño (supongo que hijo que Fernán Ruiz). Se trata de Fernán Ruiz Cabeza de Vaca, hermano de Rodrigo Rodríguez de Castil Sarracín. Los Cabeza de Vaca, según C. Estepa, formarán parte de la nobleza comarcal por el ámbito de proyección de sus intereses señoriales y Fernán Ruiz en alguna ocasión aparece vinculado a los Giron, a los que también vemos vinculados otros miembros de este amplio grupo familiar, como el propio García Fernández de Villamayor ${ }^{93}$. Fernán Ruiz también tuvo heredades y derechos en Castil Sarracín que, como su sobrino también donó al obispo de Burgos en $1242^{94}$.

\footnotetext{
${ }^{89}$ PALACÍn y Martínez, Hospital del Rey, doc. 199. De esta venta tampoco se conserva el documento original, sólo una breve noticia.

${ }^{90}$ Ibid., doc. 199.

${ }^{91}$ Los documentos en D. MANsilla, Catálogo documental del Archivo Catedral de Burgos (804-1416), Barcelona, 1971 (= MANSILLA, Catalogo de la Catedral de Burgos), docs. 633, 634, 635 y 636.

${ }^{92}$ Palacín y Martínez, Hospital del Rey, doc. 288.

${ }^{93}$ ESTEPA, Las behetrías castellanas, t. 2, p. 10, donde se indica, entre otras cosas, que Fernán Ruiz Cabeza de Vaca fue "prestamero" de Villadiego por Rodrigo González Giron. También MARTínEZ SoPENA, La Tierra de Campos Occidental, p. 377 (aunque no comparto la filiación que propone este autor de Fernán o Fernando Ruiz como hijo de un Ruy Pérez, esposo de María Nazaren o Nazarénez; puesto que según mi interpretación sería hijo de un Rodrigo Díaz).

${ }^{94}$ Mansilla, Catálogo de la Catedral de Burgos, doc. 632. Obtuvo también heredad en el Repartimiento de Sevilla en Castellán, en el término de Sanlucar, donde recibió 50 aranzadas y 6 yugadas formando parte de un grupo de caballeros de la mesnada del rey Alfonso $X$. GONZÁLEZ, Repartimiento de Sevilla, t. 2, pp. 40-41 y 234 .
} 
Por esos años también se documentan otros personajes que llevaron el apellido de Castil Sarracín, algunos de ellos sin duda eran nobles y probablemente estaban emparentados con Ordoño García o con Rodrigo Rodríguez, pero lo desconozco con exactitud ${ }^{95}$.

\section{RECAPITULACIÓN}

Entre el conjunto de los nietos de Ordoño Pérez y Urraca Fernandez podemos individualizar a cuatro familias: la de García Fernández de Villamayor, la de Ordoño Pérez de Cabia, la de Vela García y la de Ordoño García de Castil Sarracín. Las relaciones de parentesco exactas existentes entre ellos no las conocemos con el detalle que desearíamos pero, aparte de la evidencia del documento de 1194, la existencia de esas relaciones se refleja también en la frecuencia con que unos personajes actúan como fiadores de otros del mismo grupo familiar en las ventas de sus bienes ${ }^{96}$. Quizás no se pueda generalizarse completamente, pero lo más frecuente es que en las compraventas durante la Edad Media los fiadores pertenezcan al grupo familiar del vendedor ${ }^{97}$.

Como decíamos al comienzo de estas páginas, para varios de los descendientes de Ordoño Pérez es más apropiado hablar de nobleza regional que de nobleza estrictamente local; para otros cabría hablar de una proyección comarcal. La reconstrucción genealógica y prosopográfica que he intentado realizar es la única vía posible para poder obtener alguna idea sobre su patrimonio. Se trata de un método méramente aproximativo, por su puesto,

\footnotetext{
${ }^{95}$ En 1223 se documenta a Ferrán Martínez de Castil Sarracín en PALACÍN y MARTíNEZ Hospital del Rey, doc. 95. En 1227 Ferrán Alfonso de Castil Sarracín en Ibid., doc. 121. En 1227 y 1242 Diego Fernández de Castil Sarracín en MENÉNDEZ PIDAL, Documentos lingüísticos, doc. 179, y en MANSILla, Catálogo de la Catedral de Burgos, doc. 636. En 1248 Alfonso García, hijo de García Gómez de Castil Sarracín en PALACín y MARTínez, Hospital del Rey, doc. 272. En 1251 María Domínguez de Castil Sarracín en Ibid., doc. 289. Entre los testigos de ese documento figuran Rođrigo Ordóñez, hijo de Ordoño García de Castil Sarracín y Diego Fernández de Castil Sarracín.

${ }^{96}$ En 1200 Ordoño Pérez de Cabia fue fiador en la venta de los bienes de Ordoño Garçía de Castil Sarracin en Sotragero a Esteban de la Cruz. En 1216 Ordoño García de Castil Sarracin fue fiador en la venta de los bienes de Vela García en Vilviestre de Munó a García Fernández de Villamayor. Ese mismo año Vela Garcia fue fiador en la venta de los bienes de Ordoño García en la misma villa a García Fernández de Villamayor. En 1222 Rodrigo Rodríguez fue fiador en la venta de los bienes de Ordoño García en Espinosa y Quintanilla al monasterio de Silos. En 1223 Ordoño García de Castil Sarracín fue fiador en la venta de los bienes de su sobrino Rodrigo Rodríguez de Castil Sarracín en Padilla de Abajo al monasterio de Villamayor de Treviño. En 1232 Fernando Ruiz (Cabeza de Vaca) fue fiador en el cambio que hizo su sobrino Alfonso Ruiz, hijo de Rodrigo Rodríguez de Castil Sarracín, con el monasterio de Las Huelgas de heredades en varios lugares en la zona de Villadiego y Treviño. El mismo fue fiador en la venta de los bienes que Alfonso Ruiz tenía en Castil Sarracín al obispo de Burgos. Y acompañado de Juan Fernanández el Niño (primo del vendedor) también en la venta de ọtras heredades ese mismo año al obispo de Burgos en el mismo lugar. Véanse los documentos citados más arriba.

97 "La fianza nace de la solidaridad de la familia y constituye por esto para los parientes un derecho y a la vez un deber"; R. PRIETO BANCES, Donación de una iglesia a un altar, "Cuadernos de Historia de España", XVII (1952), pp. 105-141, y la cita en p. 140; aunque según R. FERNÁNDEZ ESPINAR en La compraventa en el Derecho medieval español, "Anuario de Historia del Derecho Español”, XXV (1955), pp. 293-528, especialmente pp. 507-510, este caracter familiar del fiador no es exclusivo, pero lo cierto es que es muy frecuente.
} 
pero la carencia de otro tipo de documentación más explícita lo convierte en el único posible. Además, los escasos documentos que como el testamento de Mayor Ordóñez ofrecen una información más completa, vienen a confirmar la impresión obtenida. Los descendientes de Ordoño Pérez concentraban su patrimonio por el territorio entre el Arlanzón y el Duero, pero no de manera general, sino concentrándose en zonas concretas, pudiendo destacarse tres: la zona de Villadiego, las zonas próximas a la ciudad de Burgos y la comarca de Muñó y la ribera del Duero. En cada una de esas zonas poseían heredades en un grupo más o menos reducido de villas, generalmente próximas entre sí. Tampoco faltan referencias a propiedades en otras zonas lejanas como Madrid o Toledo. Como es lógico, resulta bastante frecuente que varios miembros del grupo familiar posean heredades en las mismas villas.

Esta proyección regional se concreta también en los enlaces con otros linajes más poderosos. García Fernández (de Villamayor) pertenecía a esta familia amplia, Urraca García, hija de García Ordóñez, se casó con Pedro Núñez de Guzmán y conviene recordar también el probable matrimonio de Ordoño Pérez II de Cabia con una Sandoval. Además, ya se ha indicado la opinión de algunos autores de que los descendientes de Ordoño Pérez y Urraca Fernández debían pertenecer a una rama secundaria del linaje de Aza.

$\mathrm{Al}$ detenerme en el estudio de este grupo familiar mi intención ha sido, en parte, mostrar las posibilidades que ofrece la documentación, tanto sus limitaciones como su potencial. A este ejemplo pueden añadirse otros muchos; pero he pretendido únicamente ofrecer un ejemplo que, en cierta medida, pueda tomarse como modelo y muestre algunos aspectos que me parecen importantes, como los enlaces de parentesco entre distintos sectores de la nobleza. También me interesa concretar con el mayor grado de precisión posible los dominios territoriales puesto que ese elemento, es decir la proyección del radio de actuación patrimonial, es uno de los principales elementos para definir los distintos sectores dentro de la baja nobleza.

Fecha de recepción del artículo: octubre 2008.

Fecha de aceptación y versión final: junio 2009. 

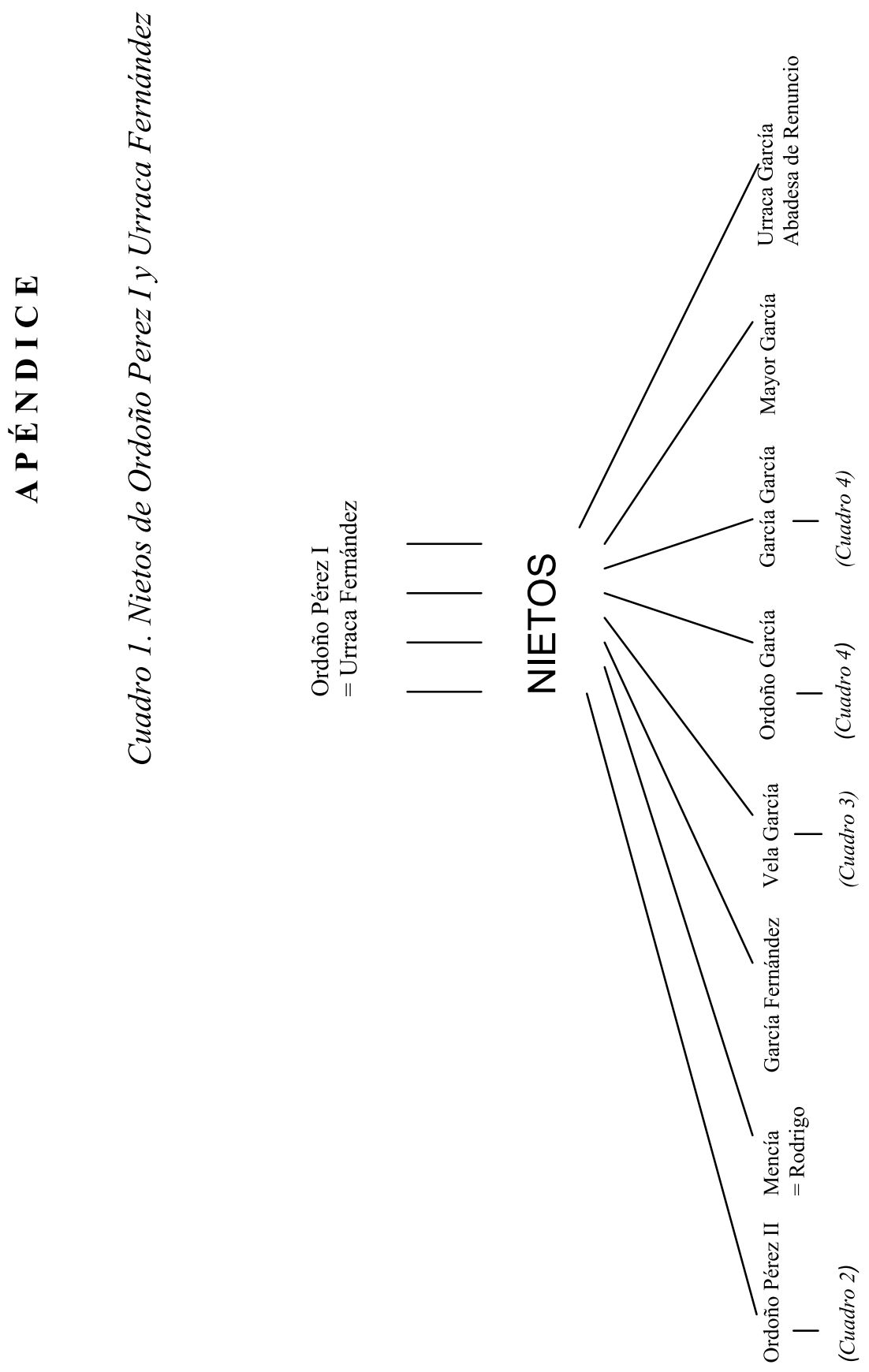

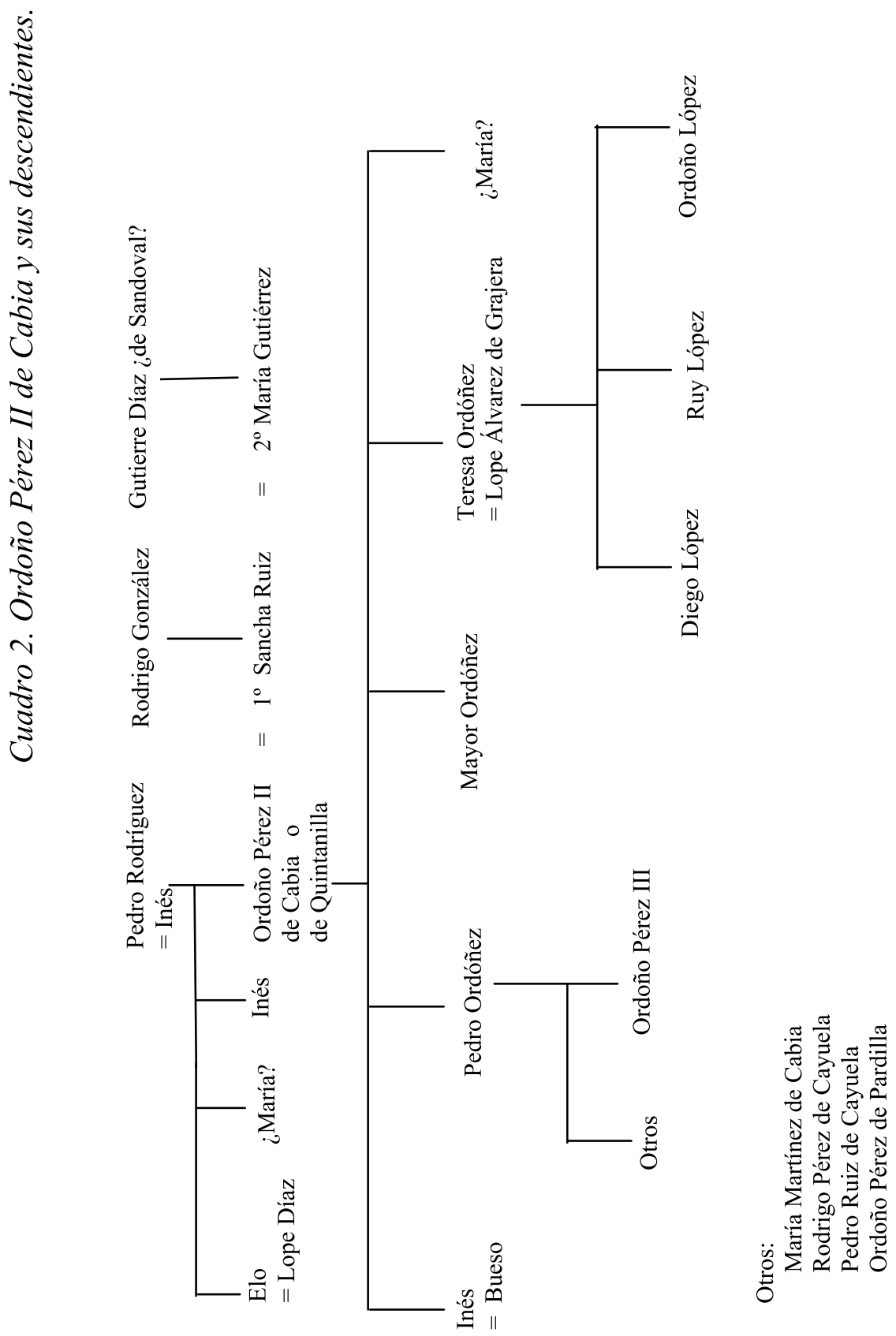

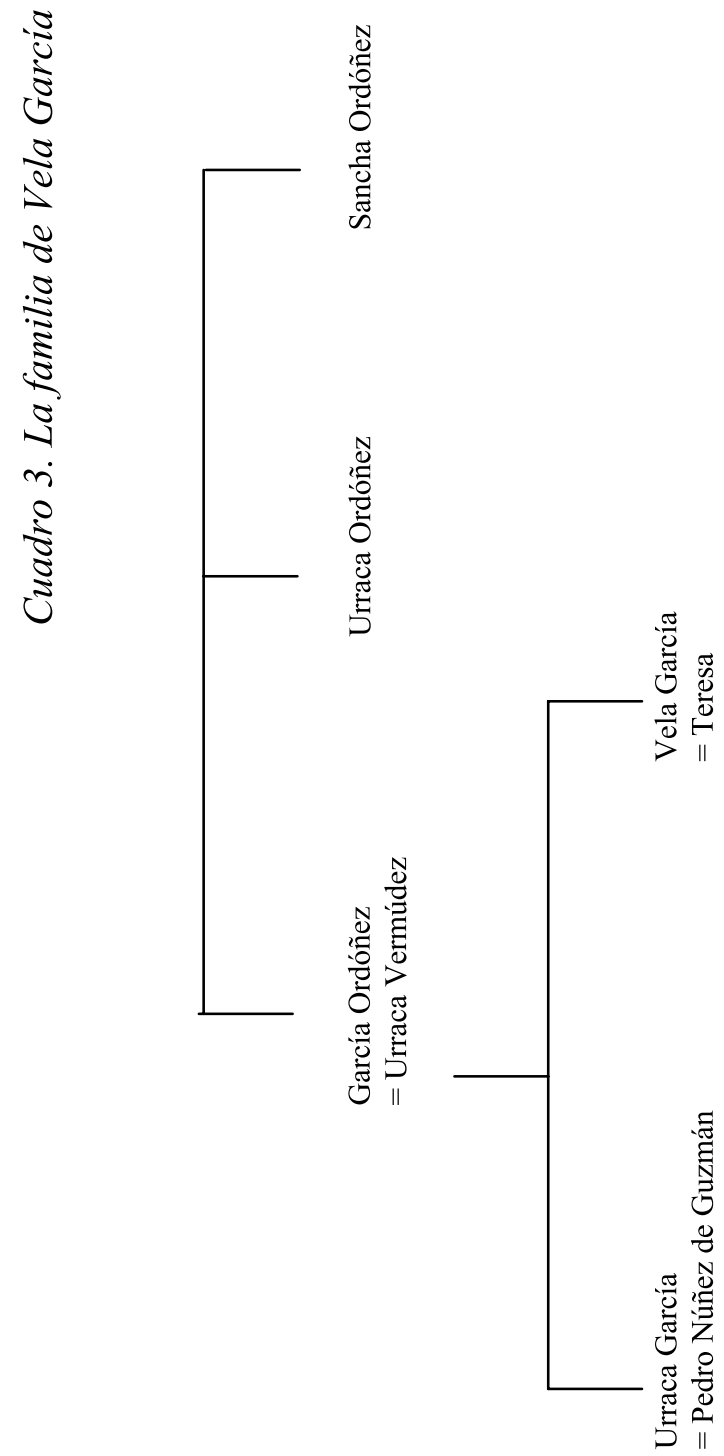


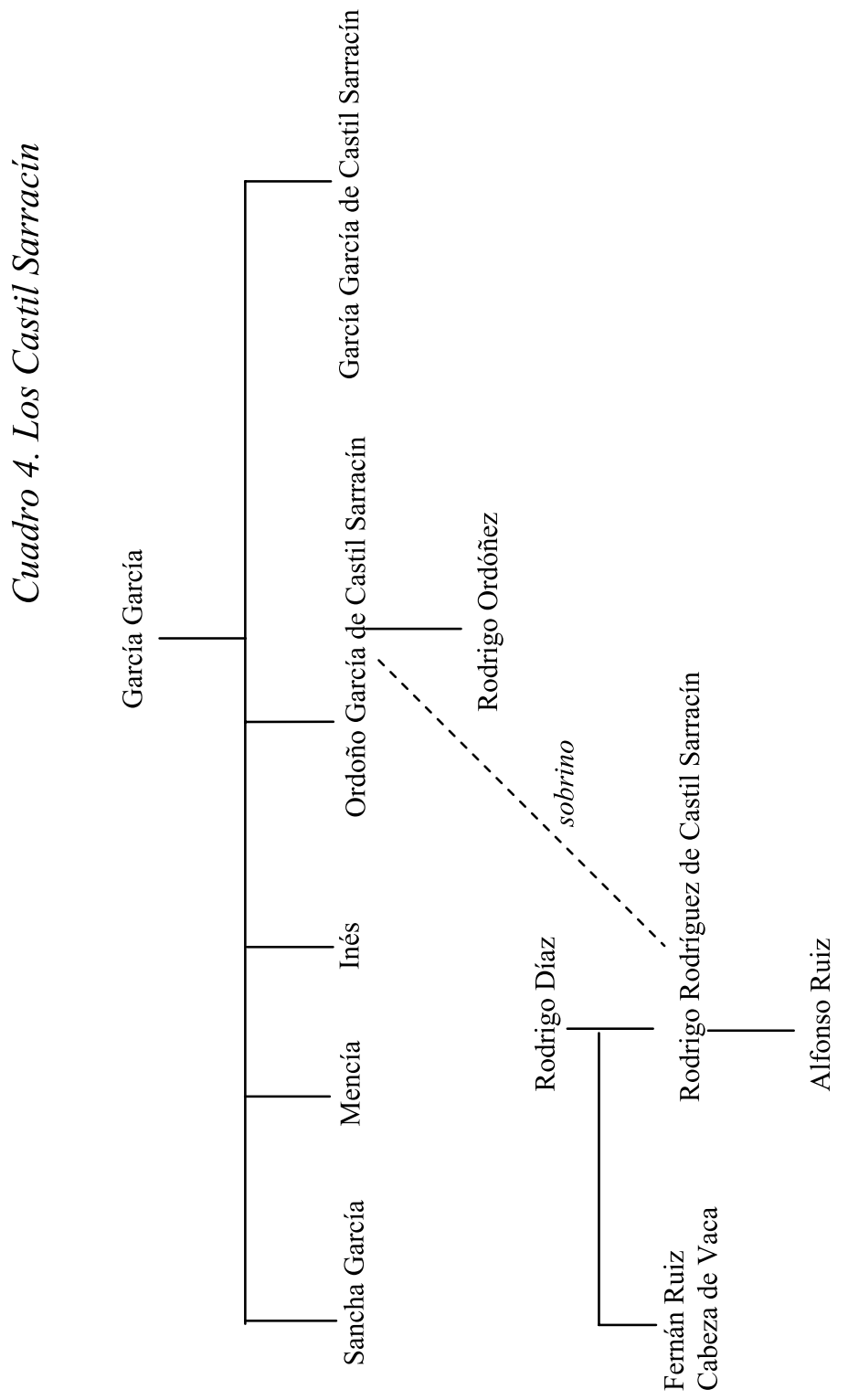




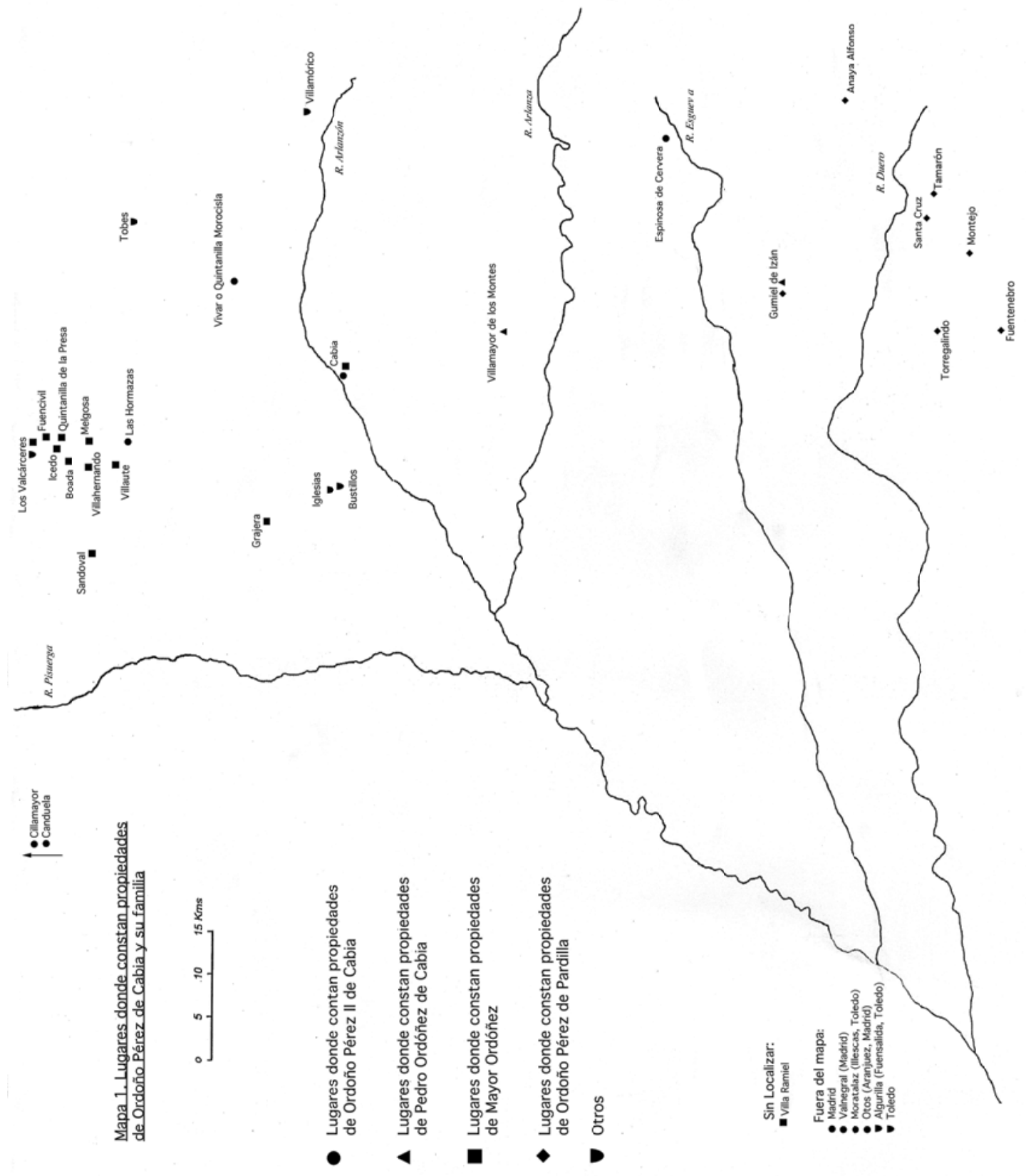




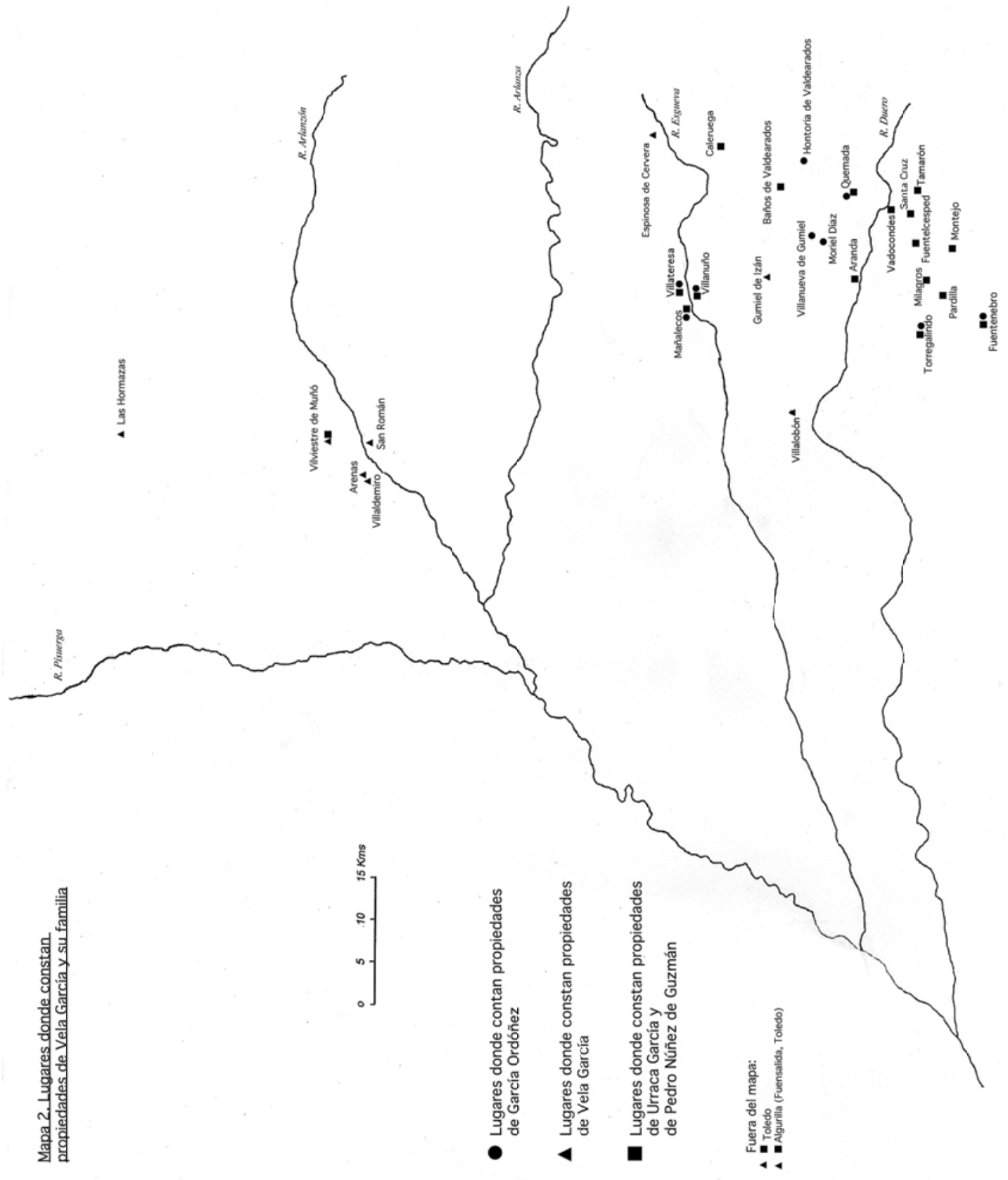




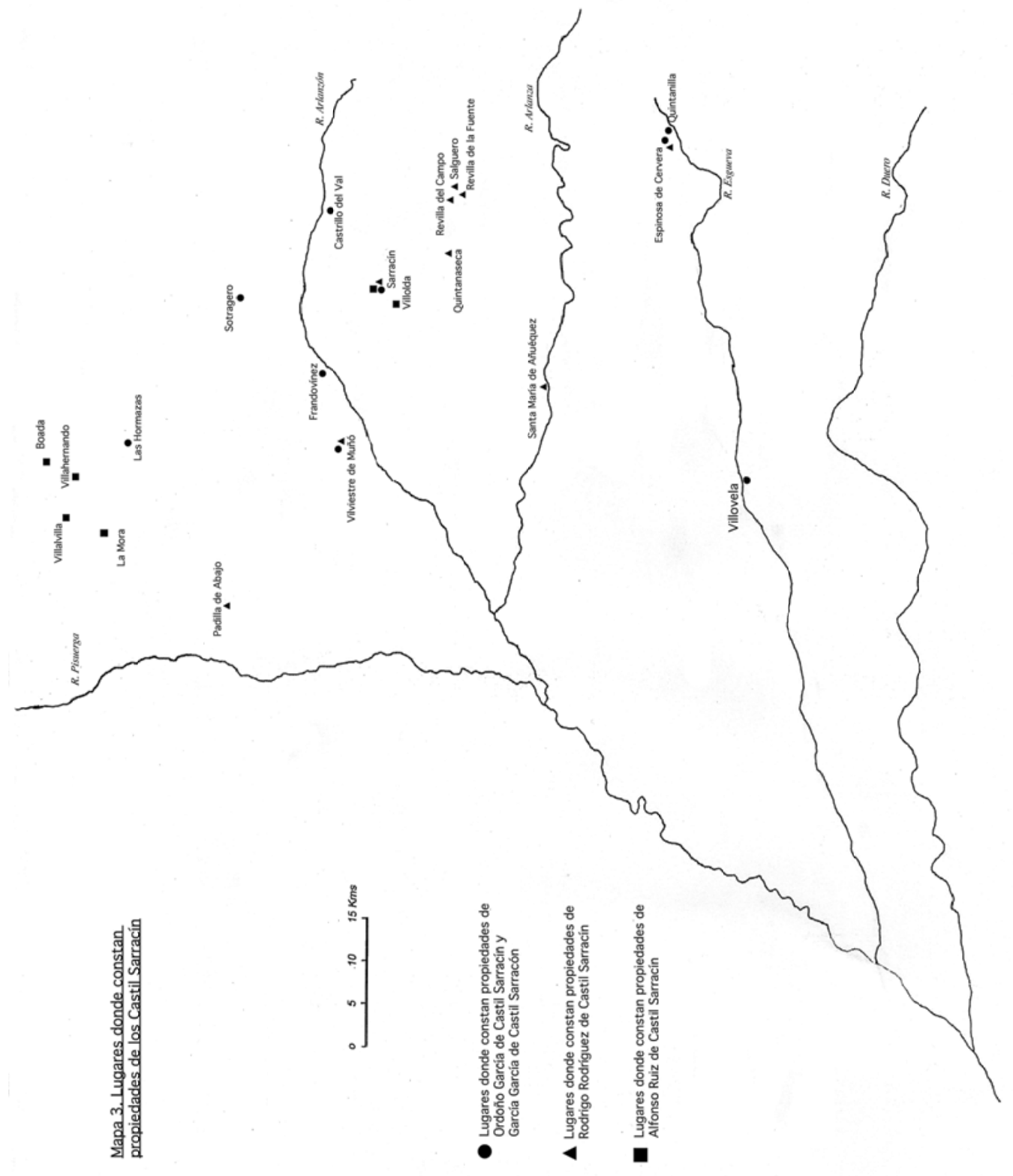

